\title{
WestVirginiaUniversity
}

THE RESEARCH REPOSITORY @ WVU

Graduate Theses, Dissertations, and Problem Reports

2017

\section{Examining Diabetes, Depression and Suicide in Middle-Aged and Older Adults}

Kimberly Morton

Follow this and additional works at: https://researchrepository.wvu.edu/etd

\section{Recommended Citation}

Morton, Kimberly, "Examining Diabetes, Depression and Suicide in Middle-Aged and Older Adults" (2017). Graduate Theses, Dissertations, and Problem Reports. 6269.

https://researchrepository.wvu.edu/etd/6269

This Thesis is protected by copyright and/or related rights. It has been brought to you by the The Research Repository @ WVU with permission from the rights-holder(s). You are free to use this Thesis in any way that is permitted by the copyright and related rights legislation that applies to your use. For other uses you must obtain permission from the rights-holder(s) directly, unless additional rights are indicated by a Creative Commons license in the record and/ or on the work itself. This Thesis has been accepted for inclusion in WVU Graduate Theses, Dissertations, and Problem Reports collection by an authorized administrator of The Research Repository @ WVU. For more information, please contact researchrepository@mail.wvu.edu. 
Examining Diabetes, Depression and Suicide in Middle-Aged and Older Adults

Kimberly Morton

Thesis submitted

to the Eberly College of Arts and Sciences

at West Virginia University

in partial fulfillment of the requirements for the degree of

Master of Science in

Psychology

Amy Fiske, Ph.D., Chair
Barry Edelstein, Ph.D.
Nicholas Turiano, Ph.D.
Department of Psychology
Morgantown, West Virginia

2016

Keywords: suicide, diabetes, middle-aged, older adults

Copyright 2016 Kimberly Morton 


\begin{abstract}
Examining diabetes, Depression and Suicide in Middle-Aged and Older Adults
\end{abstract}

\title{
Kimberly Morton
}

Rates of suicide in the United States are highest in middle-aged and older adults compared to younger age groups. These rates are alarming and point to the need for suicide prevention research in middle-aged and older adult populations. Depression is the most well-established independent risk factor for death by suicide. Some health conditions are also associated with risk of suicide above and beyond depression. Diabetes is often co-morbid with depression (clinical and subclinical depression). However, research examining diabetes and risk of suicide is less clear. In the current study, the first aim was to examine diabetes, vision impairment and depressive symptoms. Controlling for age, gender, marital status, weight and education, diabetes predicted depressive symptoms in a multiple linear regression. Impaired vision partially explained the association between diabetes and depressive symptoms. Additionally, marital status and gender both had an interaction effect in the relation between diabetes and depressive symptoms. The second aim examined diabetes and risk of suicide; however, due to low power, the findings could not be interpreted. Future studies should examine diabetes and risk of suicide with a larger U.S. sample of middle-aged and older adults. The diabetes-depressive symptoms findings are important when considering practice and policy related to mental health in middleaged and older adult populations who are diagnosed with diabetes. 


\section{TABLE OF CONTENTS}

$\begin{array}{ll}\text { Introduction } & 1\end{array}$

Diabetes and depression $\quad 5$

$\begin{array}{ll}\text { Gender, diabetes and depression } & 8\end{array}$

Vision impairment, diabetes and depression $\quad 9$

$\begin{array}{ll}\text { Diabetes and suicide } & 10\end{array}$

$\begin{array}{ll}\text { Statement of the problem and hypotheses } & 14\end{array}$

$\begin{array}{ll}\text { Method } & 16\end{array}$

$\begin{array}{ll}\text { Participants } & 16\end{array}$

$\begin{array}{ll}\text { Materials and procedures } & 17\end{array}$

$\begin{array}{ll}\text { Analyses } & 20\end{array}$

$\begin{array}{ll}\text { Results } & 22\end{array}$

$\begin{array}{ll}\text { Sample characteristics } & 22\end{array}$

Aim 1: Diabetes and depressive symptoms 23

Aim 2: Diabetes, depressive symptoms and death by suicide 24

$\begin{array}{ll}\text { Exploratory analyses } & 25\end{array}$

$\begin{array}{ll}\text { Discussion } & 26\end{array}$

References 33

$\begin{array}{ll}\text { Tables } & 46\end{array}$

$\begin{array}{ll}\text { Figures } & 58\end{array}$

$\begin{array}{ll}\text { Appendices } & 65\end{array}$ 
Examining Diabetes, Depression and Suicide in Middle-Aged and Older Adults

Centers for Disease Control and Prevention (CDC) data indicate that there is a spike in rate of suicide during middle-age as well as in the oldest old, i.e., individuals $\geq$ age 85 ; therefore, research in this area is imperative to continue to identify risk factors that contribute to suicide in middle-age and older adult populations. The rate of suicide is 12.7 per 100,000 people in the United States; however, the rate for individuals 65 and older is 15.3 per 100,000 people in the U.S., and, for individuals age $85+$, the rate increases to 16.9 per 100,000 in the U.S. (Health Status and Determinants, 2013). Sweden's rate of suicide in middle-aged and older adults per 100,000 people is similar to rates in the U.S.: $45-54$ years, 19.0 ; 55-64 years, 17.9 ; $65-74$ years, 16.7; and 75+, 16.9. In 2013, after examining suicide rates for 1999-2010 in the U.S., the CDC reported that rate of suicide among middle-aged adults (i.e., 35 to 64 ) increased by $28 \%$. Moreover, because non-violent suicide deaths in older adults can mistakenly be classified as accidental overdoses of prescription drugs or attributed to medical conditions, reported statistics may actually be underestimating death by suicide in the older adult population (Batty, Kivimaki, Park, \& Jee, 2012). These statistics are alarming and point to the need for suicide prevention research in middle-aged and older adult populations. This paper focused on two possible risk factors: diabetes and depression.

Throughout this paper, the terms depression, major depression and clinical depression all refer to a diagnosis of depression (e.g., major depressive disorder according to the Diagnostic Statistical Manual of Mental Disorders-5). Depressive symptoms, subclinical depression, clinically significant depressive symptoms or minor depression refer to symptoms of depression that do not necessarily meet diagnostic criteria. Finally, a portion of the studies referenced throughout this paper did not define depression in the original study; therefore, every effort was 
made to accurately define depression when discussing these particular studies throughout this paper.

A myriad of variables have been linked to suicide in late life, but depression is the most well-established. For instance, in a study comparing 822 older adults who died by suicide and 944 controls who died in motor vehicle accidents, researchers reported that older adults with depression (according to medical records/ICD codes) were seven times more likely to die by suicide when compared to older adults without depression (Quan, Arboleda-Flórez, Fick, Stuart, \& Love, 2002). Moreover, in an article reviewing late-life suicide, Conwell, Van Orden and Caine (2011), report that major depressive disorder is most related to death by suicide when compared to other psychiatric illnesses. For example, in a case-controlled psychological autopsy study where informants of 70 subjects age 60 and over who died by suicide and 100 older adults living in the community were interviewed, findings indicate that $86 \%$ of subjects who died by suicide had a psychiatric illness, with major depressive disorder being most prevalent, compared to just $9 \%$ of subjects in the control group (Chiu et al., 2004). In another psychological autopsy study, Conwell and colleagues (1996) reported that older age predicted mood disorders in those who died by suicide. In an earlier psychological autopsy study investigating mental illness, alcohol use and depression in 100 (aged 15-65+) individuals who died by suicide, results indicated that $85 \%$ of the study's subjects met criteria for major depressive disorder (as rated and agreed upon by three psychiatrist interviewers); additionally, men and women aged 45-64 and 65+ who died by suicide had higher rates of depressive symptoms when compared to subjects aged 15-24 and 25-44 who died by suicide (Barraclough, Bunch, Nelson, \& Sainsbury, 1974). Researchers examining suicide behavior in late life indicate a link between physical illness and increased risk of suicide in older adults (reviewed by Fiske, O’Riley, \& Widoe, 2008; 
Quan et al, 2002; Shelef et al., 2014). In a study comparing younger and older adults who died by suicide, findings indicate that older adults often have more physical illnesses, and are more likely to visit a primary care practitioner within six months of suicide (Tadros \& Salib, 2007). In a population-based study, researchers reported several physical illnesses that were associated with an increased risk of suicide in older adults, including chronic lung cancer, heart disease and seizure disorder (Juurlink, Herrmann, Szalai, Knopp, \& Redelmeier, 2004). Because of the association between physical illness and increased risk of suicide, examining specific illnesses and their relation to increased risk of suicide in middle-aged and older adults is an important piece of suicide prevention research. The current study focused on one type of physical illness, diabetes mellitus (DM), and the death by suicide relation.

In order to demonstrate the importance of investigating diabetes and suicide in middleaged and older adults, this paper discusses the relation between diabetes and depression, possible mechanisms that may explain the diabetes-depression relation, gender differences, and negative physical health outcomes affecting individuals with diabetes, specifically, vision impairment. Finally, the existing literature examining diabetes and suicide-related behaviors will be reviewed. These steps help establish the rationale for the main objectives of the current study, which examined the association among diabetes, depression and suicide in middle-aged and older adults.

Diabetes affects over 29 million Americans, and, for many individuals, can be an extremely difficult disease to manage. Diabetes is a chronic illness that affects the body’s ability to produce and use insulin. Insulin converts sugar and other foods into energy that our bodies require for survival (Diabetes.org, 2015). Individuals with type 1 diabetes do not produce insulin, and, therefore, require daily insulin injections. Individuals with type 2 diabetes may produce 
insulin, but the body has an inability to properly use the insulin, so oral medication is required to induce the breakdown of sugars; however, some patients with type 2 diabetes may also require insulin injections in addition to oral medication. Latent Autoimmune Diabetes (LADA) is a less common type of diabetes that typically develops around age 30. LADA is typically managed with diet and oral medication in the first six months of diagnosis, but eventually requires insulin treatment (Stenstrom, Gottsater, Bakhtadze, Berger, Sundkvist, 2005). Individuals with type 1 and type 2 diabetes generally use a small device (after lancing the side of the finger tip) that provides a measure of blood-sugar level. An individual's blood sugar level will help determine the person's medication/insulin dosage, timing and type of meals that should be consumed, and whether or not the individual is within the normal blood-sugar level range. Men and women 65 years and older have the highest rates of diabetes compared to all other age groups (CDC, 2011; Kirkman et al., 2012). Common comorbidities in individuals with diabetes are hypertension, cardiovascular disease, stroke, kidney disease, lower-limb amputation, and blindness or vision impairment (Diabetes.org, 2015). Moreover, the diabetes literature demonstrates strong evidence supporting the association between diabetes and depression; in fact, those with diabetes are twice as likely as those without diabetes to have clinically significant depressive symptoms (Winkley, 2008).

\section{Diabetes and depression}

The occurrence of depressive symptoms in patients with diabetes has been studied for many years. Early studies of diabetes in the late 1600s by physician Thomas Willis described patients as “...[having] excessive melancholy...similar to fits or other depressions and breakdowns of the animal spirit...” (Breznoščáková \& Nagyova, 2013). Because diabetes continues to affect millions of Americans, with highest rates in individuals 65 and older, 
examining diabetes and comorbid depression is an area of interest for many researchers (American Diabetes Association, 2014; Kirkman et al., 2012). For example, modern studies provide strong evidence that supports what has been seen in the medical community for decades - individuals with diabetes have an increased incidence of major depression when compared to the general population (Rubin \& Peyrot, 2001). In a study examining depression, anxiety and diabetes-related emotional distress in middle-aged and older adults, findings indicate that older adults with diabetes have significantly higher levels of depressive symptomatology than older adults without diabetes (Poulsen \& Pachana, 2012). Further, in a population-based cohort study investigating diabetes and depression, researchers reported that prevalence and incidence rates of depressive disorders were significantly higher in those with diabetes when compared to the general population (Huang, Lin, Lee, Chang, Chiu, 2012). Similar findings were reported in a population-based retrospective cohort study. At a six and a half year follow-up, Hsu, Su, Chang, Sung, Lyu, \& Chen (2012) reported that the incidence of depressive symptoms was 1.8 times higher in those with diabetes compared to individuals without diabetes; additionally, individuals with type 2 (non-insulin dependent) diabetes had higher rates of depressive symptoms compared to those with type 1 (insulin treated) diabetes. In a 2001 meta-analysis examining co-morbid depression in people with diabetes, the authors stated that rates of depression in type 1 and type 2 diabetes were not reported in most of the original studies, therefore, prevalence rates between the two types could not be determined; however, overall, the authors concluded that depression is twice as likely to occur in those with diabetes (Anderson, Freedland, Clouse, \& Lustman, 2001). In response to excessively high rates of depression among patients with diabetes, the field coined the term “diapression” (Ciechanowski, 2011).

Investigating the link between diabetes and depression has received much attention 
throughout the years. Teasing apart possible mechanisms responsible for the diabetes-depression relation appears to be an arduous endeavor, but, an important one. Recent studies exploring diabetes and co-morbid depression have suggested that diabetes may cause small vessel pathology in the brain, similar to what is seen in vascular depression (Pimontel, Reinlieb, Johnert, Garcon, Sneed, \& Roose, 2013). Vascular depression is a proposed type of late-life depression in which lesions in specific areas of the brain affect white matter pathways that lead to the frontal cortex (Kimura, 2003). Generally, individuals thought to be suffering from vascular depression have no prior depressive episodes, are 60+ years old, no psychotic features related to depression, and no family history of mental disorders (Krishnan, Hays, \& Blazer, 1997). Just as in vascular depression, white matter hypersensitivities are often seen in individuals with diabetes and comorbid depression (Kumar, A., Thomas, Ajilore, \& Hellemann, 2009; Sheline, 2010).

Another possible explanation for the link between diabetes and depression is elevated glutamate levels (neurotransmitter related to depression). In a study using functional magnetic resonance imaging to look at brain activity in patients with type 1 diabetes and a control group (individuals without diabetes), researchers raised blood glucose levels in both groups of participants. Glutamate levels were elevated in patients with type 1 diabetes, but not in the control group. This finding suggests that increased blood glucose levels may lead to elevated glutamate in patients with diabetes, but not in those without diabetes, which may help explain the relation between diabetes and depression (Endocrine Society, 2014).

While researchers continue to investigate biological mechanisms that may explain comorbid depression in patients with diabetes, others write about the difficulty in managing and coping with diabetes. The stress and difficulty coping with diabetes may actually lead to patients 
experiencing depressive symptoms. For example, managing diabetes requires daily maintenance from patients such as self-monitoring blood-sugar level several times a day (via fingertip lancing), oral medication and/or insulin injections, close monitoring of diet, proper physical activity and care of lower-extremities, which can all be quite stressful on patients (Nguyen et al., 2012; Russell, Stevens, \& Stern, 2009). Further, individuals with diabetes and comorbid depressive symptomatology will likely have lower rates of medication adherence, poor glycemic control and increased mortality compared to those with diabetes, but who are not depressed (Gonzalez et al., 2007; Karakus \& Patton, 2011; Winkley, 2008). Because the required care for diabetes is complex, some patients believe they do not have the capability to manage, much less cope with, a diabetes diagnosis, often leaving these patients feeling hopeless and depressed (Kent et al., 2010).

Coping with diabetes is stressful and can lead to depressive symptoms; however, depressive symptoms may lead to poor self-care, such as unhealthy dietary habits, increased alcohol use, and physical inactivity, which are all risk factors for developing diabetes (Cheng, \& Boey, 2000; Kilbourne, Reynolds, Good, Sereika, Justice, \& Fine, 2005). Therefore, another area of research has demonstrated evidence for a bidirectional relation between diabetes and depression. For example, in a sample of 65,381 female nurse participants from the Nurses' Health Study, Pan and colleagues (2010) report findings that support a bidirectional relation between diabetes and depression. On one hand, findings indicate that depressed mood is moderately associated with developing type 2 diabetes and, on the other hand, having diabetes increases the likelihood of developing depression. Results also indicate that women taking antidepressants are at an even greater risk of developing type 2 diabetes compared to those who are not taking antidepressants. Pan and colleagues offer two possible explanations for this 
particular finding: individuals on anti-depressants may have more severe depression or a history of depression, or anti-depressants themselves may actually increase the risk of developing diabetes. Moreover, to help explain the bidirectional relation, Pan and colleagues propose that (1) there may be biochemical changes occurring in the brain related to the disease itself, or treatment of the disease, that may result in the increased risk of depressive symptomatology, or (2) due to the stress of living with the disease, diabetes may lead to depressed mood. Other studies have reported similar findings; for instance, researchers examining the association between depressive symptoms and glucose metabolism in a sample of individuals 50 years of age and older from the English Longitudinal Study of Ageing, reported a bidirectional relation between depressive symptoms and diabetes in individuals age 52 to 64 years (Demakakos, Zaninotto, \& Nouwen, 2014).

\section{Gender, diabetes and depression}

Some studies examining diabetes and depression report that women with type 2 diabetes are twice as likely to have depressive symptomatology when compared to men with type 2 diabetes, which is not dissimilar from rates of depression for men and women in the general population (Costa, Campos, \& Costa, 2014; Penckofer, 2012). However, a handful of studies indicate that certain groups of women with diabetes may have more negative health outcomes than men with diabetes. For instance, using data from the Health and Retirement Study (HRS), researchers examined physical disability in men and women with and without diabetes (Chiu \& Wray, 2011). The results suggest that women with diabetes have significantly higher rates of physical disability when compared to men with diabetes. This finding was established across all ages in the HRS sample. Moreover, women with diabetes, across all age groups, have higher rates of impaired vision and mobility limitations when compared to men with diabetes (CDC, 
2011). In a study investigating biological risk factors of depression in men and women with diabetes, higher rates of depressive symptoms in men were associated with increased complications of diabetes and obesity (Tsirogianni, Kouniakis, Baltatzi, Lavrentiadis, \& Alevizos, 2010). It appears that rates of depressive symptoms in men and women with diabetes may differ depending on biopsychosocial factors such as obesity, physical disability, and complications of the disease.

\section{Vision impairment, diabetes and depression}

Fluctuation of vision is common in those with diabetes, often leading to severe vision impairment and a decrease in quality of life (Fenwick et al., 2012). Furthermore, impaired vision is also associated with depressed mood (Bookwala \& Lawson, 2011; Carrière et al., 2013;

Kempen et al., 2012; McDonnall, 2009; Van der Aa, 2013). The relation between low vision and depressive symptoms is often reported in studies examining late-life depression as well as studies investigating vision impairment and depressive symptoms in individuals with diabetes. For instance, in a prospective cohort study examining depressive symptoms in patients with type 2 diabetes, researchers reported comorbid depression and diabetes increased the risk of developing diabetic retinopathy (Sieu, Katon, Lin, Russo, Ludman, \& Ciechanowski, 2011). At the 5-year follow-up, statistically significant results indicated that $22.9 \%$ of subjects with a baseline Patient Health Questionnaire (PHQ-9) score above 10 (indicating possible major depression) developed diabetic retinopathy compared to $19.7 \%$ in the group with PHQ-9 scores below 10 (indicating no depression). Sieu and colleagues (2011) also reported that a one point increase on the PHQ-9 was associated with a 3\% increase in risk of diabetic retinopathy.

Because individuals with impaired vision have difficulty continuing to engage in activities they once enjoyed such as shopping, reading, or driving themselves to attend social 
gatherings, quality of life often decreases (Fenwick et al., 2012). In a study examining disability and social support as mediators of the relation between low vision and depressive symptoms in a sample of community dwelling older adults, Kempen, Ranchor, Ambergen, \& Zijlstra (2014) reported that activity of daily living (ADL) limitations partially mediated the association between low vision and depressive symptoms. In another study investigating conditions commonly associated with vision loss in older adults, Crews, Jones, and Kim (2006) reported that depressive symptoms are a common comorbid condition among older adults who have visual impairment (i.e., difficulty seeing even with corrective lenses or cannot see at all). Crews et al. also reported that older adults with both vision loss and diabetes had significantly more difficulty walking and climbing stairs, shopping, and socializing when compared to individuals who had vision loss or diabetes, but not both. Additionally, when asked to rate their health status compared to one year ago, older adults with both vision loss and diabetes rated their health status as worse more often than individuals with only vision loss or diabetes.

\section{Diabetes and suicide}

Because the relation between diabetes and depressive symptoms has been wellestablished, and we know that depression is a major risk factor for suicide-related behaviors, the next step is to investigate what is known about the association between diabetes and death by suicide. To effectively introduce the topic of diabetes and suicide, this portion of the paper will separately discuss suicide ideation, suicide attempts and death by suicide in relation to diabetes, as these should be viewed and treated as different phenomena.

First, a portion of the literature provides evidence to support an association between diabetes and suicide ideation in young, middle-age, and older adult populations (Goldston, Kovacs, Ho, Parrone, \& Stiffler, 1994; Goldston et al., 1997; Lutz, Morton, Turiano, \&Fiske, 
2016; Pompili et al., 2009). Moreover, the literature also indicates specific factors that are strongly associated with diabetes and suicide ideation such as type of diabetes, treatment of disease, and duration of disease. For instance, in a study examining quality of life and suicide risk, Pompilli et al.(2009) discovered that women with type 1 diabetes had more suicide ideation than men with diabetes, and that individuals with type 1 DM had more suicide ideation than individuals with type 2 DM. Additionally, in a systematic review of 20 studies (after meeting rigorous inclusion criteria) examining diabetes and suicide ideation or suicide behavior, Pompili et al. (2014) reported that individuals with type1 diabetes were at an increased risk (61\%) for suicide ideation compared to those without diabetes. Lastly, a study examining factors related to suicide ideation in patients with diabetes discovered that use of insulin injections, longer duration of diabetes, and poor glycemic control were all determined to be risk factors for suicide ideation (Lee, H., Hahm, \& Lee, 2014). It appears that individuals with diabetes are at an increased risk for suicide ideation; however, it may depend on moderating factors such as type of diabetes and how long an individual has had the disease.

In addition to the association between diabetes and suicide ideation, researchers have also discovered a positive association between diabetes and suicide attempts. For instance, in a study examining suicidality among African Americans with type 1 diabetes, researchers reported that individuals with type 1 diabetes were 3 to 4 times more likely to attempt suicide compared to individuals without diabetes (Roy, A., Roy, M., \& Janal, 2010). Additionally, individuals with diabetes who had previous suicide attempts were more likely to be female, depressed, and report a history of childhood trauma, when compared to individuals with diabetes who had never attempted suicide. Pompili and colleagues (2014) suggest that type 1 diabetes is associated with increased risk for suicide, but amount of risk has not been determined. Moreover, using a 
convenience sample of 145 patients with newly diagnosed type 2 diabetes (within 24 months), Myers and colleagues (2013) examined past suicide attempts and history of suicide. Results indicated that $9.7 \%$ of patients had a history of attempted suicide, and 38.2\% met criteria for major depressive disorder (MDD). Lastly, diabetes was related to increased risk of suicide attempts in a population-based study examining physical illness and risk of suicide and suicide attempts (Bolton, Walld, Chateau, Finlayson, \& Sareen, 2015). According to the literature, it appears that individuals with diabetes may be at an increased risk for suicide attempts; however, this relation might be better explained by comparing type of diabetes and risk of suicide attempts.

Studies that have examined the relation between diabetes and death by suicide report inconsistent findings. Moreover, because the research on diabetes and death by suicide is limited, this paper includes findings from studies investigating diabetes and suicide in young, middle-aged and older adult samples. For instance, data from The Korean Cancer Prevention Study, a cohort study of 1,329,525 individuals age 30-95 at time of data collection, were used to determine if diabetes and high blood glucose levels were associated with increased risk of suicide (Batty, Kivimaki, Park, \& Jee, 2012). At a 14-year follow-up, Batty and colleagues obtained corresponding death records for individuals who died by suicide $(n=472)$. Results indicated that diabetes was associated with an increased risk for death by suicide in both men and women; however, for men, type 2 diabetes was more strongly associated with death by suicide when compared to those with type 1 diabetes. A population-based study using a mixed-aged Swedish sample, determined that diabetes was associated with a moderate increase in suicide risk for men, but not for women (Crump, C., Sundquist, K., Sundquist, J., \& Winkleby, M.A., 2014). Moreover, researchers investigating cause of death among 8,212 individuals diagnosed with type 
1 diabetes between January 1, 1965 and December 31, 1979 from Japan, Israel, the United States, and Finland obtained death records for 147 individuals who died by January 1, 1985 (Diabetes Epidemiology Research International Mortality Study Group, 1991). Findings from this cross-cultural study indicated that the majority of deaths were attributed to complications of type 1 diabetes such as kidney disease. However, suicide was the major cause of death in individuals from Finland with type 1 diabetes when compared to cause of death in individuals with type 1 diabetes from Japan, Israel and the U.S. (Diabetes Epidemiology Research International Mortality Study Group, 1991). In another study examining physical illnesses and suicide among Canadians 55 years and older, after controlling for depressive symptoms, researchers concluded that diabetes was not associated with an increased risk for death by suicide when compared to individuals who died in motor vehicle accidents (Quan, Arboleda-Flórez, Fick, Stuart, \& Love, 2002). However, some limitations should be considered when interpreting these results; for instance, suicide could be disguised as motor vehicle accidents. Moreover, according to the American Diabetes Association there are about eight million undiagnosed cases of diabetes, therefore, it is difficult to know if all diabetes cases were included in the sample since Canada may have similar rates of undiagnosed cases of diabetes.

Overall, not enough research exists to determine, one way or another, if diabetes is associated with an increased risk for suicide in middle-aged and older adults; however, because findings are inconsistent, and other research appears to support an association between diabetes and suicide ideation, the diabetes-death by suicide relation deserves further examination.

Another phenomenon garnering attention in the diabetes literature is insulin-related suicide. For example, researchers investigating reports from a regional poison control center found that $89.4 \%$ of insulin overdoses $(\mathrm{N}=160)$ involved suicidal or parasuicidal cases (von 
Mach, 2004). After becoming aware of insulin related suicide case reports, Löfman, Hakko, Mainio, Timonen, \& Räsänen (2012), gathered Northern Finland suicide data for years 1988 to 2010 (2489 suicides: 2030 men, 459 women). Individuals who had diabetes and died by suicide were compared to those who also died by suicide but did not have diabetes. Individuals with type 1 diabetes had more depression when compared to those with type 2 diabetes or without diabetes (44.4\%, 23.5\%, and 19.9\%, respectively). Additionally, individuals with type 1 diabetes used self-poisoning as method of suicide more often than those with type 2 diabetes or without diabetes (48.1\%, 31.4\%, and 18.0\%, respectively). Lastly, in individuals with type 1 diabetes, use of insulin as method of suicide accounted for half of the self-poisoning cases, compared to only $13 \%$ in individuals with type 2 diabetes. There is a plethora of research concerning undercounted suicides, and prescription drug overdose is just one factor associated with the underestimation of suicide (Increase in Suicide Rates Underestimated, 2010; Rockett, 2010; Rockett, Kapusta, \& Coben, 2014). Because insulin overdoses can appear to be accidental, we may be underestimating rate of suicides in individuals with diabetes and access to insulin.

\section{Statement of the problem and hypotheses}

The diabetes-depression relation is well-established, and research in this area continues to expand in an effort to better understand presumed mechanisms that may explain the association between diabetes and depression. The diabetes research provides evidence for a bi-directional relation between diabetes and depression, as well as biological risk factors such as obesity and uncontrolled blood sugar that may explain rates of depression in those with diabetes. Individuals with diabetes will likely experience depressive symptomatology, and may also endorse suicide ideation, which are both major risk factors for suicide. Considering that suicide is the $10^{\text {th }}$ leading cause of death in the United States, ongoing research is needed to better understand risk 
factors that are associated with suicide. Moreover, because there is still much to learn and understand concerning diabetes and death by suicide in middle-aged and older adult populations, the current study's goal was to initiate a project using a large sample of middle-aged and older adults from the Swedish Twin Registry. Learning more in this area will assist in the development and dissemination of appropriate suicide-prevention and at-risk programs for middle-aged and older adults. Additionally, because individuals with diabetes are likely to experience mild to severe vision impairment and, even daily vision fluctuations, the relation between low vision and depressed mood in middle-aged and older adults with diabetes was examined (Cigolle, Lee, Langa, Lee, Tian, \& Blaum, 2011). Further, lack of clarity exists concerning gender differences; therefore, gender differences among diabetes, depression and suicide was also examined using exploratory data analyses. Overall, the current study aimed to add something meaningful to the suicide prevention literature and help bridge the gap among large public health issues such as diabetes, depression, and suicide in middle-aged and older adults.

The aims and hypotheses of this study were as follows:

Aim 1. Examine the link between diabetes and depressive symptoms in middle-aged and older adults.

Hypothesis 1. Individuals with diabetes will have higher rates of depressive symptoms compared to those without diabetes, based on evidence indicating depressive symptoms are significantly higher in people with diabetes compared to that of the general population (Rubin \& Peyrot, 2001).

Hypothesis 1b. Using the diabetes subgroup, time since diagnosis will predict depressive symptoms. 
Hypothesis 2. Individuals with type 2 diabetes will have higher rates of depressive symptoms compared to those who do not have type 2 diabetes, based on evidence demonstrating that type 2 diabetes is associated with higher rates of depressive symptoms when compared to type 1 diabetes (Hsu, Su, Chang, Sung, Lyu, \& Chen, 2012).

Hypothesis $2 \boldsymbol{b}$. In the diabetes subgroup, type of diabetes will predict depressive symptoms.

Hypothesis 3. Vision impairment will partially mediate the relation between diabetes and depressive symptoms in middle-aged and older adults, based on (1) evidence supporting the relation between diabetes and vision loss (Fenwick et al., 2012), and (2) evidence supporting the relation between low vision and depressive symptoms among older adults and (Crews, Jones, \& Kim, 2006).

Aim 2. To examine associations among diabetes, depressive symptoms, vision impairment and suicide in middle and late-life.

Hypothesis 4. Individuals with diabetes will have an increased risk of death by suicide when compared to individuals without diabetes and, if this relation holds true, depressive symptoms will partially mediate the relation between diabetes and risk of suicide.

Hypothesis $4 \boldsymbol{b}$. Vision impairment will partially explain the relation between diabetes and risk of suicide.

\section{Method}

\section{Participants}

Participant data from the Swedish Twin Registry (STR), Screening Across the Lifespan Twin study (SALT), were used to examine diabetes, depression and death by suicide (Pedersen, Lichtenstein, \& Svedberg, 2002). Data collection for STR began in the late 1950s for the purpose of examining the effects of alcohol use and smoking behavior on cancer and 
cardiovascular disease while controlling for genetic factors that may predispose individuals to certain diseases. Parishes throughout Sweden were contacted in order to obtain information regarding twin births occurring between 1886 and 1925. Once twin status was established, questionnaires were sent during1960-1961 to same-sexed twins living in Sweden who were born in 1925 or earlier. Other questionnaires were sent in 1963, 1967 and 1970. Individuals who did not respond to the 1963 questionnaire or had missing information, received the 1970 questionnaire. This group of twins is referred to in STR as the old-cohort, which consists of 10,945 pairs of twins. In 1973, questionnaires were sent to individuals born from 1926 to 1958, i.e., the middle-cohort, which consists of 13,665 pairs of twins.

SALT was one of several studies conducted with the twins from the Swedish Twin Registry. SALT data were collected from 1998-2002 and include twin and non-pair twins (i.e., cases where only one twin responded to survey) born in 1958 and earlier (Lichtenstein, 2002). There were 52, 080 individuals who were SALT eligible. The total number of SALT respondents was 44,919 (Lichtenstein et al., 2006).

\section{Materials and Procedure}

For the purposes of the current study, secondary data analysis was performed using data that were collected as part of the original SALT study and are linked with the Swedish National Cause of Death Register. Researchers first initiated contact with potential participants through postal mail in an effort to introduce the SALT study. Next, respondents were contacted by telephone and, if respondent agreed, either an immediate computer assisted telephone interview took place, or a researcher would call back at a later time. The telephone interview consisted of several questions inquiring about past and present medical conditions. Participants were assessed for depression, anxiety and, for participants 65 years and older, cognitive impairment. 
Other data collected during telephone interviews included, but not limited to, information related to marital status, education, tobacco and alcohol-use and several health conditions.

Items from SALT interview. For the current study, several variables from SALT were examined: diabetes diagnosis, type of diabetes, age when diagnosed with diabetes, intervention used to treat diabetes (e.g., insulin injection), vision impairment (i.e., cannot be corrected with lenses), and a measure of depressive symptoms. Age, weight, sex, education and marital status were used as covariates in the current study. See Appendix A for SALT items.

Diabetes diagnosis. Participants were presented with a question asking about several different metabolic diseases, diabetes being one of the answer choices. In follow-up questions, respondents were asked “at what age did you get diagnosed with diabetes?” Participants could respond by entering the age or year he or she was diagnosed. In another follow up question, respondents were asked whether or not a doctor told the participant the type of diabetes he or she was diagnosed with, and respondents were provided with several options, including adult-onset diabetes, juvenile-onset diabetes, type 1, type 2, insulin dependent diabetes mellitus (IDDM), and non-insulin dependent diabetes mellitus (NIDDM). For the current study, SALT participants who responded type1, IDDM, or juvenile-onset were placed in the type 1 group. Participants who responded type 2, NIDDM or adult-onset were placed in the type 2 group.

Diabetes treatment. Participants were presented with two questions regarding current and past diabetes treatment options used: “what treatments have you received?” and "what treatment are you getting now?” For both questions, answer choices included insulin injections, diet, or pills. For the current study, individuals who did not indicate type of diabetes, the type of treatment variable was used as an alternative way of categorizing the diabetes subgroup into type 1 or type 2.Participants who responded “insulin injections” were placed in the type 1 group. 
Participants who responded “pills or diet” were placed in the type 2 group. If a respondent responded to both pills and insulin injection answer choices, he or she was placed in the type 1 group since individuals with diabetes requiring insulin injections, typically, have type 1 diabetes.

Depression symptoms. The 11-item CESD is a measure of depressive symptoms used in both clinical and research settings. The 11-item scale is highly correlated (Pearson's $r=.95$ ) with the original 20-item CESD (Kohout, Berkman, Evans, \& Cornoni-Huntley, 1993). Kohout et al. also reported acceptable internal consistency for the 11-item CESD demonstrated by Cronbach’s alpha, .81. In the current study’s sample, Cronbach’s alpha =.80. The 11-item CESD includes items that represent all four subscales (Depressed Affect- 3 items, Positive Affect- 2 items, Somatic- 4 items, Interpersonal- 2 items). During the SALT participant interviews, respondents were asked how they felt in the past week, using a 4-point scale $(0=$ Never or almost never, $1=$ Seldom, 2 = Often, 3 = Always or almost always) to rate each item (items five and eight are reversed scored). See Appendix B for the entire 11-item measure. The established cut-point of 6, often used with the 11-item CESD, indicates depressive symptomatology (Kohout, Berkman, Evans, \& Cornoni-Huntley, 1993).

Total scores on the 11-item CESD variable were prorated for individuals who answered at least nine of the 11 items by summing completed items, dividing this sum by the number of completed items, and then multiplying by eleven (the number of items on the CESD). There were 1,797 participants that were missing CESD data, but, after prorating, there were only 1,549 missing. The mean was similar with $(\mathrm{M}=3.81, \mathrm{SD}=4.27)$ and without $(\mathrm{M}=3.78, \mathrm{SD}=4.27)$ including prorated data.

Vision impairment. In the SALT interview, participants were asked whether or not they had vision impairment, and were provided with three response choices (no, one eye, both eyes). 
Vision impairment was operationally defined in the salt interview as being different from near or far sightedness - it is vision loss that cannot be corrected with lenses.

Marital status. Marital status is dichotomous (married, unmarried). The married category includes living with partner, cohabitated, and married. Unmarried includes divorced, single, never married, and widowed.

Education. The education item is a continuous variable (0-20), indicating level of education.

Weight. Weight was originally recorded in kilograms. For the current study, weight was transformed to pounds for all participants.

Cause of death registry. The Cause of Death (COD) Register provides statistics on deaths that occurred in Sweden, beginning in 1961, and is updated yearly (Socialstyrelsen, 2015). Participant data from SALT were matched with data from the COD Register. The current study used the most recent COD data available (i.e., latest death date, December 31, 2012).

\section{Analyses}

Aim 1: Diabetes and depressive symptoms. All analyses were performed in SAS 9.3, unless otherwise noted (e.g., mediation analyses were performed in Mplus). To examine the relation between diabetes and depressive symptoms, type of diabetes was tested as a potential moderator, and vision impairment as a potential mediating variable.

The first hypothesis for Aim 1 stated that individuals with diabetes would have higher rates of depressive symptoms than those without diabetes. Before performing analyses, assumptions of linear regression were tested. To make parameter estimate interpretations easier and decrease multicollinearity between interaction terms, continuous variables were centered (i.e., depressive symptoms, age, education, weight, and duration of disease). Using the entire 
sample and holding age, gender, weight, marital status and education constant, the relation between diabetes and depression was tested using multiple linear regression. Hypothesis $1 \mathrm{~b}$ stated that duration of disease would predict depressive symptoms. Duration of disease was centered. Next an interaction term was created (durationXtypediabetes). The interaction term was included in a multiple linear regression to determine if it predicted depressive symptoms in the diabetes subgroup.

To test the second hypothesis, which stated that individuals with type 2 diabetes would have higher rates of depressive symptoms, first, type 1 and type 2, were dummy coded so that each one was compared to the reference group (those without diabetes) and entered simultaneously in a multiple linear regression. Next, to test hypothesis $2 \mathrm{~b}$, using only the diabetes subgroup in a multiple linear regression, type of diabetes (dummy coded so that type 1 $=0$, type $2=1$, those without diabetes = missing) was entered to determine whether having type 1 or type 2 predicted higher rates of depressive symptoms. The third hypothesis for Aim 1 stated that vision impairment would partially mediate the relation between diabetes and depressive symptoms. A path analysis in Mplus 6.12 was used to test indirect effects of diabetes on depressive symptoms through vision impairment, controlling for demographic variables (age, gender, weight, education and marital status).

Aim 2: Diabetes, depressive symptoms and death by suicide. To examine hypothesis 4, survival analysis techniques (i.e., Poisson regression and proportional hazards modeling) were used to determine if, in this sample, diabetes was associated with an increased risk of suicide. Poisson regression and proportional hazards resulted in identical outcomes. All reported findings are Cox proportional hazards. Assumption of proportional hazards was tested before performing analyses. When working with large datasets or time-varying covariates, the Schoenfeld method is 
suggested to test the proportional hazard assumption (Allison, 2010). If the assumption is satisfied ( $p$ values greater than .05), it can be assumed that the Schoenfeld residuals are not correlated with time or a function of time (Allison, 2010). In the current study, the proportional hazards assumption was satisfied for all variables except the interview date variable $(p=.03)$. Reported depressive symptoms and vision impairment were tested separately, and together, for indirect effects using the product*coefficient method in Mplus.

Exploratory analyses. To determine whether or not men and women with diabetes differ in rates of depressive symptoms, using multiple regression, gender was tested as a potential moderator. Lastly, the full model was tested in a path analysis using Mplus. The model specified paths from diabetes to vision impairment and depressive symptoms, and from each of these to suicide risk.

\section{Results}

\section{Sample characteristics}

Demographic characteristics, sample sizes, frequencies, means and standard deviations, and t-scores/chi-square statistics for all variables are presented in Table 1. The diabetes subgroup had a higher percentage of men and unmarried individuals, more depressive symptoms, lower education and fewer suicides compared to the non-diabetes group. Because this is a sample from the Sweden population, it is assumed that the majority of the sample is Caucasian. The average education level for the diabetes and non-diabetes subgroups was high school. However, individuals who did not respond to the diabetes item were not included in final analyses, which resulted in a final sample size of 43,703 participants. Data from the cause of death registry (matched by twin number) was merged with SALT interview data. Over the 14-year follow-up, 
there were 9,356 deaths. See Table 1 for cause of death frequencies. Pearson's $r$ correlations for continuous variables used in analyses are presented in Table 2.

\section{Aim 1: Diabetes and depressive symptoms}

First, a simple linear regression was performed to determine if diabetes predicted depressive symptoms. Diabetes significantly predicted depressive symptoms, $b=.94, F(1$, 43,103) $=103.09, p<.0001, R^{2}=.0024$. There was a .94 increase in reported depressive symptoms in individuals with diabetes compared to those without diabetes. Next, age, gender, marital status, weight, and years of education were included as covariates in a multiple linear regression with diabetes predicting depressive symptoms. After including covariates, the model remained statistically significant, $F(6,42,419)=416.82, p<.0001, R^{2}=.0556$. See Table 3 for parameter estimates, confidence intervals and significance statistics for individual variables.

Similar analyses were performed with the diabetes subgroup, except, rather than diabetes predicting depressive symptoms, time since diagnosis (i.e., duration of disease) was used as the main predictor. The overall model was statistically significant, $F(7,2,143)=34.55$, $p<$ $.0001, R^{2}=0.10$. Duration was statistically significant in predicting depressive symptoms. See Table 4 for parameter estimates, confidence intervals and significance statistics for individual variables. Next, an interaction term (durationXtypediabetes) was created and entered in the model to examine a possible interaction effect. The overall model was statistically significant, $F(8,2,142)=30.43, p<.0001, R^{2}=0.10$, but the interaction term was not significant. Exploratory analyses were performed to determine if duration of diabetes predicted depressive symptoms in the type 1 and type 2 subgroups. Separate multiple regressions were performed in the type 1 and type 2 diabetes groups. Duration did not predict depressive symptoms in the type 1 group, but did predict depressive symptoms in the type 2 group, $F(6,1,858)=34.18, p<$ 
$.0001, R^{2}=0.10$, suggesting that duration matters when predicting depressive symptoms for those with type 2 diabetes but not for those with type 1 diabetes. See Table 5 for parameter estimates, confidence intervals and significance statistics for individual variables.

To test hypothesis 2, dummy coded variables (diatype1, $0=$ those without diabetes and those with type 2, 1=those with type 1 diabetes; diatype2, $0=$ those without diabetes and those with type $1,1=$ those with type 2 diabetes) were entered into a multiple linear regression using the full sample to determine if rates of depressive symptoms were higher in type 1 or type 2 compared to individuals without diabetes. The full model was statistically significant ( $F(7$, $42,376)=355.07, p=.001$. Results indicated that type 1 diabetes predicted depressive symptoms $(b=1.057,95 \% C I=0.573-1.539, p=.001)$, as did type 2 diabetes $(b=.949,95 \% C I=0.754-1.144$, $p=.001$ ) (see Table 6). Next, using only the diabetes subgroup, a dummy coded variable was created so that type 1 and type 2 diabetes were compared to one another to determine whether or not the type 2 diabetes group had higher rates of depressive symptoms $(\mathrm{M}=4.68, \mathrm{SD}=4.97)$ compared to the type 1 diabetes group ( $\mathrm{M}=4.88, \mathrm{SD}=4.54)$, as stated in hypothesis 2 . While the overall model was significant $(F(5,2,150)=46.87, p=.001)$, results indicated that there was no difference in type of diabetes predicting depressive symptoms. (see Table 7).

To test hypothesis 3 , the indirect effect of diabetes on reported depressive symptoms through vision impairment, a path model was tested (covariates were included in the path analysis) using Mplus (6.12). Significant effects emerged for the total and indirect effect pathways (see Figure 1).

\section{Aim 2: Diabetes, depressive symptoms and death by suicide}

To test hypothesis 4, a proportional hazards model (i.e., Cox modeling) was used to examine diabetes predicting risk of suicide. Time on study was used as the time metric, diabetes 
was entered as the main predictor while controlling for demographic variables (sex, age, marital status, weight and education), and suicide was entered as the outcome variable $(0=$ did not die by suicide, 1=died by suicide/undetermined death). Results were not statistically significant. (see Table 8). Several follow-up analyses testing potential indirect effects, using the product*coefficient procedure in Mplus, were performed, but results were non-significant: Reported depressive symptoms was entered as a potential mediator between diabetes and suicide (see Figure 2); vision impairment was entered as a potential mediator between diabetes and suicide (see Figure 3); depressive symptoms and vision impairment were entered into one model as potential mediators between diabetes and suicide (see Figure 4). Lastly, the full model (diabetes $\rightarrow$ vision impairment $\rightarrow$ depression $\rightarrow$ suicide) was tested, and the model was not statistically significant (see Figure 5).

\section{Exploratory analyses}

To determine whether males or females with diabetes differ in rates of reported depressive symptoms, a multiple linear regression was performed with diabetes, gender and genderXdiabetes predicting reported depressive symptoms. The overall model was significant, $F(7,42,4420)=360.27, p=.001, b=-0.811,95 \% C I=-1.167--0.454, p=.001$ (see table 9). To determine where the gender differences occur, first, separate multiple linear regressions were performed for both men and women. The results indicated that women with diabetes had higher rates of reported depressive symptoms compared to men with diabetes. Women with diabetes had a $1.40(S E=.149)$ point increase on the CESD compared to men with diabetes who had a .61 $(S E=.108)$ point increase on the CESD, suggesting that, while both men and women with diabetes have more depressive symptoms compared to those without diabetes, the effect is 
stronger for women. The plotted interaction effects suggest that the effects of diabetes on depression are amplified in women compared to men (See Figure 6).

Because marital status was predictive of depressive symptoms (see Table 3 and Table 4) in hypotheses 1 and 2, marital status was tested as a potential moderator of the relation between diabetes and depressive symptoms. An interaction term was created (maritalstatusXdiabetes) and entered in a multiple linear regression predicting depressive symptoms. The overall model was significant, $F(7,42,420)=359.89, p=.001$, and the interaction term significantly predicted depressive symptoms, $b=-0.796$ ( $S E=.192), 95 \% C I=-1.172,-0.421, p=.001$ (see Table 10$)$. The plotted interaction suggests that the effects of diabetes on depressive symptoms are amplified in those who are unmarried compared to those who are married/living with a romantic partner (see Figure 7).

In lieu of performing statistical analyses to identify possible gender differences in men and women with diabetes and suicide risk, sample characteristics are presented in Table 10 for both the diabetes and non-diabetes subgroups who died by suicide. Because (1) diabetes did not predict risk of suicide and (2) there were only five suicides in the diabetes subgroup presenting descriptives for this small group was the more appropriate choice. The Descriptive statistics show that the diabetes subgroup appears to be older, to weighs more, reported more depressive symptoms, and reported being unmarried at a higher percentage compared to those in the nondiabetes group.

\section{Discussion}

The purpose of the proposed study was to determine if diabetes mellitus was associated with depressive symptoms and an increased risk of death by suicide in middle-aged and older adults. Diabetes and depression are often comorbid and, because depression is a major risk 
factor for suicide-related behavior, examining the relation between diabetes and suicide was warranted. Moreover, because a portion of the literature demonstrates differences between treatment or type of diabetes and rates of depression, this project also examined whether or not rates of depressive symptoms were different depending on type of diabetes. Additionally, because vision impairment has been found to be associated with both suicide-related behavior and depression, and also has a positive association with diabetes, the current study examined vision impairment as a potential mediator among diabetes, reported depressive symptoms and risk of suicide. Lastly, there is limited research that investigates gender differences in diabetes, depression and suicide, therefore, this study performed exploratory analyses to determine whether or not gender differences exist.

The first part of the current study examined the diabetes-depression relation, and in line with hypothesis 1 , diabetes was associated with higher rates of depressive symptoms compared to those without diabetes, which is consistent with past studies (Rubin \& Peyrot, 2001; Poulsen \& Pachana, 2012). The current study’s findings are not surprising since we know that some individuals with diabetes may have similar brain pathologies to those with vascular depression (Pimontel et al., 2013), have elevated glutamate levels (Endocrine Society, 2014), and may experience difficulty coping and managing their diabetes-related symptoms, which could all negatively influence a person’s mood and psychological well-being (Kent et al., 2010).

In the diabetes subgroup, age and marital status were negatively associated with depressive symptoms. However, education and weight were not associated with depressive symptoms. Individuals with diabetes who were not married/living with a romantic partner, reported more of depressive symptoms compared to those with diabetes who were married/living with romantic partner. One possible explanation for this finding is that married people have more 
access to daily social support, which results in more positive outcomes (Sacco \& Yanover, 2006). Overall, older people with and without diabetes reported fewer depressive symptoms compared to younger ages. For those with diabetes, one explanation for fewer depressive symptoms could be due to increased risk of mortality (selective mortality), which is prevalent in those with diabetes (Kimbro et al., 2014). Therefore, those who are healthier, live longer, and do so with fewer reported depressive symptoms.

Additionally, women with diabetes had more depressive symptoms compared to men with diabetes, which is consistent with past research (Penckofer, 2012). Moreover, compared to women without diabetes, women with diabetes report more depressive symptoms; therefore, diabetes appears to be more “depressing” for women compared to men. Women with diabetes tend to have worse health outcomes compared to men with diabetes, so it is reasonable that women with diabetes would report more depressive symptoms (Chiu \& Wray, 2011).

Another interesting finding in this sample was the positive association between duration of the disease and depressive symptoms in folks with type 2 diabetes: the longer an individual has type 2 diabetes the more likely he or she will experience an increase in reported depressive symptoms, which closely matches similar research. For instance, while examining factors associated with suicide ideation in people with diabetes, Lee and colleagues (2014) found that duration of the disease was positively associated with increased risk of suicide ideation. Therefore, when working with individuals with diabetes, particularly type 2, it is imperative to assess for depression on an ongoing basis, and not assume that these individuals habituate.

In an effort to establish which type of diabetes may be driving rates of reported depressive symptoms, the relation between type of diabetes and reported depressive symptoms was examined in a couple of different ways. First, using the entire sample, findings suggest that 
people with type 1 and type 2 diabetes indeed have higher rates of depressive symptoms compared to those without diabetes.. This is consistent with what Hsu and colleagues (2012) found in their longitudinal study examining diabetes and risk of subsequent depression. However, for the diabetes subgroup in our sample, type 1 and type 2 diabetes were both predictive of depressive symptoms.

Upon examining the indirect effects of diabetes on reported depressive symptoms, impaired vision partially explained the association between diabetes and depressive symptoms. Fluctuation of vision is common in those with diabetes and may result in subsequent vision impairment (Fenwick et al., 2012), which negatively impacts one’s ability to engage in pleasant activities (Kempen et al., 2014), and can lead to depressed mood (Bookwala \& Lawson, 2011). While the current study's sample of those with vision impairment was small, past research supports the relation among diabetes, vision impairment and depressive symptoms (Bookwala \& Lawson, 2011; Carrière et al., 2013; Crews et al., 2006; Kempen et al., 2012; McDonnall, 2009; Van der Aa, 2013). The current study went a step further by testing the indirect effects diabetes on depressive symptoms through vision impairment. Because people with diabetes may develop vision impairment, which could result in a subsequent reduction of pleasant activities and increased suicide risk (Wearn et al., 2002), assessing vision and activity level/participation on an ongoing basis is important when working with patients with diabetes.

A test of Cox proportional hazards indicated that diabetes was not associated with risk of suicide in this sample. Though the findings were not statistically significant, the direction is worth mentioning, results suggest that individuals with diabetes actually have a reduced risk of death by suicide compared to those without diabetes. One possible explanation, which will be tested in future analyses with this sample, is that diabetes (type 1 and type 2) is associated with 
dementia (Ryan, van Duinkerken, \& Rosano, 2016). Some evidence suggests that dementia has a negative association with suicide (Erlangsen, Zarit, Tu, \& Conwell, 2006), although, findings are mixed. Even though Erlangsen and colleagues (2006) found that dementia was negatively associated with dementia, in a later paper, Erlangsen, Zarit, and Conwell (2008) found that dementia did predict suicide. Therefore, dementia could potentially be interpreted as a protective factor against risk of suicide. An alternate explanation for the null findings in this study could relate to increased risk of mortality in those with diabetes-individuals who are really "bad off” die earlier from complications of diabetes whereas individuals who are "better off” live longer, and do so without thoughts of suicide. An additional explanation could be that a portion of the deaths were coded as accidental overdoses, accidents, natural causes or complications of diabetes rather than suicides, which would suggest an underestimation of suicide in this sample. Because women die by suicide at a much lower rate compared to men, especially in middle-age and late life, the non-association of diabetes and risk of suicide in this sample may be partially explained by the fact that having diabetes was actually less depressing for men compared to women. Lastly, considering the small sample size of the diabetes group, it cannot be concluded that diabetes is not associated with suicide since these findings could simply be an issue of low power.

Even with the sophisticated statistical methods, large population-based cohort study and extended follow-up time (suicide analyses), there were limitations in the current study that should be addressed. First, because this was a sample from Sweden, where prevalence rates of diabetes are lower ( 6\%) compared to the U.S. ( 11\%), the diabetes subgroup was quite small (American Diabetes Association, 2014; World Health Organization, 2016). Therefore, low power may have been an issue in the suicide analyses. Second, findings cannot be generalized beyond 
Caucasian populations. Additionally, there was no way to distinguish whether or not vision impairment was associated with diabetes; however, it is clear that vision impairment is not simply a form of normal myopia. Lastly, to determine causal relations among diabetes, vision impairment, and depression, longitudinal analyses would be necessary.

Despite the reported limitations, the current study's findings point to the need for additional research in specific areas related to diabetes, depression and suicide in middle-aged and older adults. First, future studies should examine vision impairment as a potential mediator with longitudinal data. Better detection of explanatory variables, such as impaired vision, among diabetes, depression and suicide could facilitate more effective screening tools and interventions in patients with diabetes. Second, including duration of illness in future studies, will help to better identify critical time periods where depression may be worse and suicide-related behavior could potentially increase, especially in those with type 2 diabetes. Third, examining outcomes for men and women with diabetes, by type, duration, marital status and vision impairment predicting depressive symptoms and suicide, may help determine potential gender differences and identify independent risk factors. Diabetes and increased risk of suicide in middle- and latelife should be reexamined with a larger sample of people with diabetes to more accurately determine whether or not an association exists. Lastly, including cognitive impairment as a potential moderator or, at the very least, a covariate, could be crucial in determining how diabetes and suicide are related in larger samples.

The current study reported findings that both supported and added to previous research examining diabetes, depressive symptoms and suicide in middle-aged and older adult populations. Middle-aged and older adults with diabetes reported more depressive symptoms compared to their peers without diabetes, and vision impairment partially explained the relation. 
We are unaware of any other studies that have examined vision impairment as a potential mediator of the relation between diabetes and depressive symptoms. Marital status predicted more depressive symptoms in those with and without diabetes; however, being unmarried is associated with more depressive symptoms in those with diabetes compared to those without diabetes. Regarding gender, diabetes appeared to be more depressing for women compared to men with diabetes. Lastly, duration of the disease was associated with more depressive symptoms in those with type 2 diabetes. These findings are important when considering practice and policy related to mental health in middle-aged and older adult populations. 


\section{References}

Allison, P. (2010). Survival analysis using SAS: a practical guide, second edition. Cary, NC: SAS Institute Inc.

American Diabetes Association (2014). Statistics about diabetes. National Diabetes Statistics Report. Retrieved from http://www.diabetes.org/diabetes-basics/statistics/?loc=db-

\section{$\underline{\text { slabnav }}$}

Anderson, R.J., Freedland, K.E., Clouse, R.E., Lustman, P.J. (2001). The prevalence of comorbid depression in adults with diabetes: a meta-analysis. Diabetes Care, 24(6), 1069-1078.

Baron, R. M., \& Kenny, D. A. (1986). The moderator-mediator variable distinction in social psychological research: Conceptual, strategic, and statistical considerations. Journal of Personality And Social Psychology, 51(6), 1173-1182. doi:10.1037/0022-3514.51.6.1173

Barraclough, B., Bunch, J., Nelson, B., \& Sainsbury, P. (1974). A hundred cases of suicide: Clinical aspects. The British Journal of Psychiatry, 125355-373. doi:10.1192/bjp.125.4.355

Batty, G. D., Kivimaki, M., Park, I. S., \& Jee, S. H. (2012). Diabetes and raised blood glucose as risk factors for future suicide: Cohort study of 1234927 Korean men and women. Journal of Epidemiology and Community Health, 66(7), 650-652. doi:10.1136/jech-2011-200464

Bolton, J. M., Walld, R., Chateau, D., Finlayson, G., \& Sareen, J. (2015). Risk of suicide and suicide attempts associated with physical disorders: A population-based, balancing scorematched analysis. Psychological Medicine, 45(3), 495-504.

doi:10.1017/S0033291714001639 
Bookwala, J., \& Lawson, B. (2011). Poor vision, functioning, and depressive symptoms: A test of the activity restriction model. The Gerontologist, 51, 798-808. doi:10.1093/geront/gnr051

Breznoščáková, D., \& Nagyova, I. (2013). Diabetes Mellitus. In Depression and Glucose Metabolism. Nese Kocabasoglu (Ed.) InTech, DOI: 10.5772/53467. Available from: http://www.intechopen.com/books/mood-disorders/depression-and-glucose-metabolismdiabetes-mellitus-

Carrière, I., Delcourt, C., Daien, V., Pérès, K., Féart, C., Berr, C., \& ... Ritchie, K. (2013). A prospective study of the bi-directional association between vision loss and depression in the elderly. Journal of Affective Disorders, 151, 164-170. doi:10.1016/j.jad.2013.05.071

Centers for Disease Control and Prevention (2011). Diabetes public health resource. Retrieved from http://www.cdc.gov/diabetes/statistics/complications_national.htm

Centers for Disease control and Prevention (2013). Health status 2013: Death rates for suicide, by sex, race, Hispanic origin, and age: United States, selected years 1950-2011 Retrieved from http:/www.cdc.gov/nchs/hus/contents2013.htm\#035

Cheng, T. L., \& Boey, K. W. (2000). Coping, social support, and depressive symptoms of older adults with Type II diabetes mellitus. Clinical Gerontologist: The Journal of Aging and Mental Health, 22, 15-30. doi:10.1300/J018v22n01_03

Cigolle, C. T., Lee, P. G., Langa, K. M., Lee, Y., Tian, Z., \& Blaum, C. S. (2011). Geriatric conditions develop in middle-aged adults with diabetes. Journal of General Internal Medicine, 26, 272-279. doi:10.1007/s11606-010-1510-y 
Chiu, C., \& Wray, L. A. (2011). Physical disability trajectories in older Americans with and without diabetes: The role of age, gender, race or ethnicity, and education. The Gerontologist, 51, 51-63. doi:10.1093/geront/gnq069

Chiu, H. K., Yip, P. F., Chi, J., Chan, S., Tsoh, J., Kwan, C. W., \& ... Caine, E. (2004). Elderly suicide in Hong Kong - A case-controlled psychological autopsy study. Acta Psychiatrica Scandinavica, 109, 299-305. doi:10.1046/j.1600-0447.2003.00263.x

Ciechanowski P. (2011). Diapression: an integrated model for understanding the experience of individuals with co-occurring diabetes and depression. Clinical Diabetes, 29, 43-49.

Conwell, Y., Duberstein, P. R., Cox, C., Herrmann, J. H., Forbes, N. T., \& Caine, E. D. (1996). Relationship of age and Axis I diagnoses in victims of completed suicide: A psychological autopsy study. The American Journal of Psychiatry, 153, 1001-1008

Conwell, Y., Van Orden, K., \& Caine, E. D. (2011). Suicide in older adults. Psychiatric Clinics of North America, 34, 451-468. doi:10.1016/j.psc.2011.02.002

Costa, E. G., Campos, R. P., \& Costa, E. C. (2014). Relationship between socio-demographic, clinical and psychosocial variables in patients with Type 2 Diabetes. Análise Psicológica, 32, 63-77.

Cox, D. R. (1972). Regression models and life tables. Journal of the Royal Statistical Society, 34, $187-220$.

Crews, J. E., Jones, G. C., \& Kim, J. H. (2006). Double Jeopardy: The Effects of Comorbid Conditions among Older People with Vision Loss. Journal of Visual Impairment \& Blindness, 100(Suppl), 824-848 
Crump, C., Sundquist, K., Sundquist, J., \& Winkleby, M. A. (2014). Sociodemographic, psychiatric and somatic risk factors for suicide: A Swedish national cohort study. Psychological Medicine, 44, 279-289. doi:10.1017/S0033291713000810

Demakakos, P., Zaninotto, P., \& Nouwen, A. (2014). Is the association between depressive symptoms and glucose metabolism bidirectional? Evidence from the english longitudinal study of ageing. Psychosomatic Medicine, 76, 555-561.

Diabetes Epidemiology Research International Mortality Study Group (1991). International evaluation of cause-specific mortality and IDDM. Diabetes Care, 14(1), 5560.

Diabetes.org. Diabetes basics. Retrieved April 3, 2015 from http://www.diabetes.org/diabetesbasics/

Endocrine Society. (2014). High blood sugar causes brain changes that raise depression risk. Science Daily. Retrieved February 7, 2015 from www.sciencedaily.com/releases/2014/06/140623092011.htm

Erlangsen, A., Zarit, S., Tu, X., \& Conwell, Y. (2006). Suicide among older psychiatric inpatients: An evidence-based study of a high-risk group. The American Journal of Geriatric Psychiatry, 14, 734-741.

Erlangsen, A., Zarit, S., \& Conwell, Y. (2008). Hospital-diagnosed dementia and suicide: A longitudinal study using prospective, nationwide register data. The American Journal of Geriatric Psychiatry, 16, 220-228. 
Fenwick, E. K., Pesudovs, K., Khadka, J., Dirani, M., Rees, G., Wong, T. Y., \& Lamoureux, E. L. (2012). The impact of diabetic retinopathy on quality of life: Qualitative findings from an item bank development project. Quality Of Life Research: An International Journal of Quality Of Life Aspects of Treatment, Care \& Rehabilitation, 21, 1771-1782. doi:10.1007/s11136-012-0110-1

Fiske, A., O’Riley, A., Widoe, R. (2008). Physical health and suicide in late life: an evaluative review. Clinical Gerontologist, 31(4), 31-50, doi: 10.1080/07317110801947151

Goldston, D. B., Kovacs, M., Ho, V. Y., Parrone, P. L., \& Stiffler, L. (1994). Suicidal ideation and suicide attempts among youth with insulin-dependent diabetes mellitus. Journal of the American Academy of Child \& Adolescent Psychiatry, 33, 240-246. doi:10.1097/00004583-199402000-00013

Goldston, D. B., Kelley, A. E., Reboussin, D. M., Daniel, S. S., Smith, J. A., Schwartz, R. P., \& ... Hill, C. (1997). Suicidal ideation and behavior and noncompliance with the medical regimen among diabetic adolescents. Journal of the American Academy of Child \& Adolescent Psychiatry, 36, 1528-1536.

Gonzalez, J.S., Safren, S.A., Cagliero, E., Wexler, D., Delahanty, L., Wittenberg, E.,...Grant, R. (2007). Depression, self-care, and medication adherence in type 2 diabetes: Relationships across the full range of symptom severity. Diabetes Care, 30, 2222-2227.

Health Status and Determinants. (2013). Death rates for suicide, by sex, race, hispanic origin, and age: United States, selected years 1950-2011 Retrieved from http:/www.cdc.gov/nchs/hus/contents2013.htm\#035 
Hsu, Y., Su, L., Chang, H., Sung, F., Lyu, S., \& Chen, P. (2012). Diabetes mellitus and risk of subsequent depression: A longitudinal study. International Journal of Nursing Studies, 49, 437-444. doi:10.1016/j.ijnurstu.2011.09.019

Huang, C., Lin, C., Lee, M., Chang, K., Chiu, H. (2012). Prevalence and incidence of diagnosed depression disorders in patients with diabetes: a national population-based cohort study. General Hospital Psychiatry, 34, 242-248. doi:10.1016/j.genhosppsych.2011.12.011

Increase in Suicide Rates Underestimated (2010). Retrieved from http://www.newsmedical.net/news/20101204/Increase-in-suicide-rates-underestimated.aspx

Juurlink, D.N., Herrmann, N., Szalai, J.P., Knopp, A., Redelmeier, D.A. (2004). Medical illness and the risk of suicide in the elderly. Archives of Internal Medicine, 164, 1179-1184

Karakus, C., \& Patton, L. (2011). Depression and the onset of chronic illness. Journal of Behavioral Health Services \& Research, 38, 373-382.

Kempen, G. M., Ballemans, J., Ranchor, A. V., van Rens, G. B., \& Zijlstra, G. R. (2012). The impact of low vision on activities of daily living, symptoms of depression, feelings of anxiety and social support in community-living older adults seeking vision rehabilitation services. Quality of Life Research: An International Journal of Quality of Life Aspects of Treatment, Care \& Rehabilitation, 21, 1405-1411. doi:10.1007/s11136-011-0061-y

Kempen, G. M., Ranchor, A. V., Ambergen, T., \& Zijlstra, G. R. (2014). The mediating role of disability and social support in the association between low vision and depressive symptoms in older adults. Quality of Life Research: An International Journal of Quality of Life Aspects of Treatment, Care \& Rehabilitation, 23, 1039-1043. doi:10.1007/s11136013-0536-0 
Kent, D., Haas, L., Randal, D., Lin, E., Thorpe, C. T., Boren, S. A., \& ... Martin, A. L. (2010). Healthy coping: Issues and implications in diabetes education and care. Population Health Management, 13, 227-233. doi:10.1089/pop.2009.0065

Kilbourne, A. M., Reynolds, C. I., Good, C. B., Sereika, S. M., Justice, A. C., \& Fine, M. J. (2005). How does depression influence diabetes medication adherence in older patients? The American Journal of Geriatric Psychiatry, 13, 202-210. doi:10.1176/appi.ajgp.13.3.202

Kimbro, L. B., Mangione, C. M., Steers, W. N., Duru, O. K., McEwen, L., Karter, A., \& Ettner, S. L. (2014). Depression and all-cause mortality in persons with diabetes mellitus: Are older adults at higher risk? Results from the Translating Research into Action for Diabetes Study. Journal of The American Geriatrics Society, 62, 1017-1022. doi:10.1111/jgs.12833

Kirkman, M. S., Briscoe, V. J., Clark, N., Florez, H., Haas, L. B., Halter, J. B., \& ... Swift, C. S. (2012). Diabetes in older adults: A consensus report. Journal of the American Geriatrics Society, 60(12), 2342-2356. doi:10.1111/jgs.12035

Krishnan, K. R., Hays, J. C., \& Blazer, D. G. (1997). MRI-defined vascular depression. The American Journal of Psychiatry, 154, 497-501.

Kohout, F. J., Berkman, L. F., Evans, D. A., \& Cornoni-Huntley, J. (1993). Two shorter forms of the CES-D Depression Symptoms Index. Journal of Aging and Health, 5, 179-193. doi:10.1177/089826439300500202

Kumar, A., Gupta, R., Thomas, A., Ajilore, O., \& Hellemann, G. (2009). Focal subcortical biophysical abnormalities in patients diagnosed with type 2 diabetes and 
depression. Archives of General Psychiatry, 66, 324-330.

doi:10.1001/archgenpsychiatry.2008.548

Lee, H., Hahm, M., \& Lee, S. G. (2014). Risk of suicidal ideation in diabetes varies by diabetes regimen, diabetes duration, and HbA1c level. Journal of Psychosomatic Research, 76, 275-279. doi:10.1016/j.jpsychores.2014.02.003

Lichtenstein, P., De Faire, U., Floderus, B., Svartengre, M., Svedberg, P., Pedersen, N.L. (2002). The Swedish Twin Registry: a unique resource for clinical, epidemiological and genetic studies. Journal of Internal Medicine, 252, 184-205

Lichtenstein, P., Sullivan, P.F., Cnattingius, S., Gatz, M., Johansson, S., Carlström, E., ...Pedersen, N. (2006). The Swedish Twin Registry in the Third Millennium: An Update. Twin Research and Human Genetics, 9, 875-882

Löfman, S., Hakko, H., Mainio, A., Timonen, M., \& Räsänen, P. (2012). Characteristics of suicide among diabetes patients: A population based study of suicide victims in Northern Finland. Journal of Psychosomatic Research, 73, 268-271. doi:10.1016/j.jpsychores.2012.08.002

Lutz, J., Morton, K. Turiano, N., Fiske, A. (2016). Health conditions and passive suicidal ideation in the survey of health, aging, and retirement in europe. The Journals of Gerontology, Social Sciences, 71, 936-946. doi: 10.1093/geronb/gbw019

McDonnall, M. C. (2009). Risk factors for depression among older adults with dual sensory loss. Aging \& Mental Health, 13, 569-576. doi:10.1080/13607860902774410

Moussavi, S., Chatterji, S., Verdes, E., Tandon, A., Patel, V., Ustun, B. (2007). Depression, chronic diseases, and decrements in health: Results from the World Health Surveys. Lancet, 370, 851-858 
Muth`́en, L.K. and Muth’en, B.O. (1998-2014). Mplus Users Guide. Seventh Edition. Los Angeles, CA: Muth'en \& Muth'en.

Myers, A. K., Grannemann, B. D., Lingvay, I., \& Trivedi, M. H. (2013). Brief report: Depression and history of suicide attempts in adults with new-onset Type 2

Diabetes. Psychoneuroendocrinology, 38, 2810-2814.

doi:10.1016/j.psyneuen.2013.06.013

Nguyen, H., Arcury, T., Grzywacz, J., Saldana, S., Ip, E., Kirk, J., ... Quandt, S.A. (2012). The association of mental conditions with blood glucose levels in older adults with diabetes. Aging \& Mental Health, 16, 950-957. doi.org/10.1080/13607863.2012.688193

Pan, A., Lucas, M., Sun, Q., et al. (2002). Bidirectional association between depression and type 2 diabetes mellitus in women. Archives of Internal Medicine, 170, 1884-1891. doi:10.1001/archinternmed.2010.356

Pedersen, L., Lichtenstein, P., Svedberg, P., (2002). The swedish twin registry in the third millennium. Twin Research, 5, 427-432.

Penckofer, S. M., Ferrans, C., Mumby, P., Byrn, M., Emanuele, M. A., Harrison, P. R., \& ... Lustman, P. (2012). A psychoeducational intervention (SWEEP) for depressed women with diabetes. Annals of Behavioral Medicine, 44, 192-206. doi:10.1007/s12160-0129377-2

Pimontel, M. A., Reinlieb, M. E., Johnert, L. C., Garcon, E., Sneed, J. R., \& Roose, S. P. (2013). The external validity of MRI-defined vascular depression. International Journal of Geriatric Psychiatry, 28, 1189-1196

Pompili, M., Lester, D., Innamorati, M., De Pisa, E., Amore, M., Ferrara, C., \& ... Girardi, P. (2009). Quality of life and suicide risk in patients with diabetes mellitus. Psychosomatics: 
Journal of Consultation and Liaison Psychiatry, 50(1), 16-23.

doi:10.1176/appi.psy.50.1.16

Pompili, M., Forte, A., Lester, D., Erbuto, D., Rovedi, F., Innamorati, M., \& ... Girardi, P. (2014). Suicide risk in type 1 diabetes mellitus: A systematic review. Journal of Psychosomatic Research, 76, 352-360. doi:10.1016/j.jpsychores.2014.02.009

Poulsen, K., Pachana, N. (2012). Depression and anxiety in older and middle-aged adults with diabetes. Australian Psychologist, 47, 90-97.

Préville, M., Hébert, R., Boyer, R., Bravo, G., \& Seguin, M. (2005). Physical health and mental disorder in elderly suicide: A case-control study. Aging \& Mental Health, 9, 576-584. doi:10.1080/13607860500192973

Quan, H., Arboleda-Flórez, J., Fick, G. H., Stuart, H. L., \& Love, E. J. (2002). Association between physical illness and suicide among the elderly. Social Psychiatry and Psychiatric Epidemiology, 37, 190-197. doi:10.1007/s001270200014

Rockett, I. H. (2010). Counting suicides and making suicide count as a public health problem. Crisis: The Journal of Crisis Intervention and Suicide Prevention, 31, 227-230. doi:10.1027/0227-5910/a000071

Rockett, I. H., Kapusta, N. D., \& Coben, J. H. (2014). Beyond suicide: Action needed to improve self-injury mortality accounting. The Journal of the American Medical Association Psychiatry, 71, 231-232. doi:10.1001/jamapsychiatry.2013.3738

Roy, A., Roy, M., \& Janal, M. (2010). Suicide attempts and ideation in African-American type 1 diabetic patients. Psychiatry Research, 179(1), 53-56. doi:10.1016/j.psychres.2010.06.004 
Rubin, R. R., \& Peyrot, M. (2001). Psychological issues and treatments for people with diabetes. Journal of Clinical Psychology, 57, 457-478. doi:10.1002/jclp.1041

Russell, K., Stevens, J., \& Stern, T. (2009). Insulin overdose among patients with diabetes: a readily available means of suicide. Primary Care Companion to the Journal of Clinical Psychiatry. 11, 258-262.

Ryan, C. M., van Duinkerken, E., \& Rosano, C. (2016). Neurocognitive consequences of diabetes. American Psychologist, 71, 563-576. doi:10.1037/a0040455

Sacco, W. P., \& Yanover, T. (2006). Diabetes and Depression: The Role of Social Support and Medical Symptoms. Journal of Behavioral Medicine, 29, 523-531. doi:10.1007/s10865006-9072-5

Shah, A. (2010). Old age psychiatry and geriatric medicine admissions and elderly suicide rates in England. International Psychogeriatrics, 22, 502-504.

doi:10.1017/S1041610209991700

Shelef, A., Hiss, J., Cherkashin, G., Berger, U., Aizenberg, D., Baruch, Y., \& Barak, Y. (2014). Psychosocial and medical aspects of older suicide completers in Israel: A 10-year survey. International Journal of Geriatric Psychiatry, 29, 846-851. doi:10.1002/gps.4070

Sheline, Y., Pieper, C., Barch, D., Welsh-Boehmer, K., McKinstry, R., MacFall, J., D’Angelo, G., ... Doraiswamy, M.(2010). Support for the vascular depression hypothesis in late-life depression results of a 2-site, prospective, antidepressant treatment trial. Archives of General Psychiatry, 67, 277-285. doi:10.1001/archgenpsychiatry.2009.204

Sieu, N., Katon, W., Lin, E. H., Russo, J., Ludman, E., \& Ciechanowski, P. (2011). Depression and incident diabetic retinopathy: A prospective cohort study. General Hospital Psychiatry, 33, 429-435. doi:10.1016/j.genhosppsych.2011.05.021 
Socialstyrelsen. (2015). Cause of Death Register. Retrieved from http://www.socialstyrelsen.se/register/dodsorsaksregistret

Stenstrom, G., Gottsater, A., Bakhtadze, E., Berger, B., Sundkvist, G. (2005). Latent autoimmune diabetes in adults: definition, prevalence, beta-cell function, and treatment. Diabetes, 54(supplemental 2), s68-72. doi: 10.2337/diabetes.54.suppl_2.S68

Tadros, G., \& Salib, E. (2007). Elderly suicide in primary care. International Journal of Geriatric Psychiatry, 22, 750-756. doi:10.1002/gps.1734

Tsirogianni, E., Kouniakis, F., Baltatzi, M., Lavrentiadis, G., \& Alevizos, M. (2010). Biological factors associated with depression in patients with type II diabetes mellitus. Psychiatriki, 21, 115-125.

Van der Aa, H. P., Van Rens, G. B., Comijs, H. C., Bosmans, J. E., Margrain, T. H., \& Van Nispen, R. A. (2013). Stepped-care to prevent depression and anxiety in visually impaired older adults - design of a randomized controlled trial. BMC Psychiatry, 13, doi:10.1186/1471-244X-13-209

von Mach, MA. (2004). Epidemiological assessment of 160 cases of insulin overdose recorded in a regional poisons unit. International Journal of Clinical Pharmacology Therapeutics. 42, $277-80$

Waern, M., Rubenowitz, E., Runeson, B., Skoog, I., Wilhelmson, K., \& Allebeck, P. (2002). Burden of illness and suicide in elderly people: Case-control study. British Medical Journal, 324, 1355-1358. doi:10.1136/bmj.324.7350.1355

Winkley, K. (2008). The epidemiology of depression in diabetes. European Diabetes Nursing, 5, 91-96. doi:10.1002/edn.117 
World Health Organization (2016) Diabetes: Diabetes country profiles 2016. Retrieved from http://www.who.int/diabetes/country-profiles/swe_en.pdf?ua=1 
Table 1

Sample Characteristics (diabetes, $\mathrm{N}=2,301$; non-diabetes, $\mathrm{N}=41,402$ )

\begin{tabular}{|c|c|c|c|c|}
\hline & $\begin{array}{c}\text { Diabetes } \\
M(\mathrm{SD}) / \\
n(\%)\end{array}$ & $\begin{array}{c}\text { Non-Diabetes } \\
M(\mathrm{SD}) / \\
n(\%)\end{array}$ & $t(\mathrm{df})$ & $\chi^{2}$ \\
\hline Age & $\begin{array}{c}65.14(10.70) \\
2,301\end{array}$ & $\begin{array}{c}58.50(10.57) \\
41,402\end{array}$ & 29.32(43701)*** & -- \\
\hline Gender (Female) & $\begin{array}{c}1,098 \\
(47.72 \%)\end{array}$ & 22,293 (53.85\%) & -- & $32.89 * * *$ \\
\hline Years of Education & $\begin{array}{c}9.20(3.00) \\
2,277\end{array}$ & $\begin{array}{c}10.50(3.25) \\
41,132\end{array}$ & $20.45(2580.7) * * *$ & -- \\
\hline Marital Status & & & -- & $77.49 * * *$ \\
\hline Married & 1,485 (64.5\%) & 30,199 (72.96\%) & & \\
\hline Unmarried & $816(34.5 \%)$ & 11,195 (27.04\%) & & \\
\hline Weight (lbs.) & $\begin{array}{c}175.51(32.16) \\
2,236\end{array}$ & $\begin{array}{c}159.99(28.86) \\
40,747\end{array}$ & $16.59(2436.7)^{* * *}$ & -- \\
\hline Depressive & $\begin{array}{c}4.72(4.91) \\
2,240\end{array}$ & $\begin{array}{c}3.76(4.22) \\
40,867\end{array}$ & $8.91(2,424) * * *$ & -- \\
\hline Symptoms ${ }^{\mathrm{a}}$ & & & & \\
\hline Cause of Death & & & -- & 4.92 \\
\hline Suicide & $5(.5 \%)$ & $72(.99 \%)$ & & \\
\hline Undetermined & 0 & $18(.25 \%)$ & & \\
\hline Other & 1013 (99.5\%) & 7214 (98.77\%) & & \\
\hline Vision Impairment & & & -- & $145.11^{* * *}$ \\
\hline No & 1180 (84.47\%) & 24,284 (93.10\%) & & \\
\hline Yes & 217 (5.53\%) & $1,801(6.90 \%)$ & & \\
\hline Diabetes & 2,301 & -- & -- & -- \\
\hline Type 1 & 305 (13.3\%) & -- & & \\
\hline
\end{tabular}


$\begin{array}{lll}\text { Type } 2 & \text { 1,965 }(86.7 \%)\end{array}$

Duration (years)

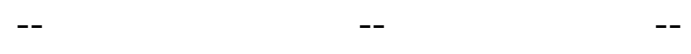

Type 1

$26.56(16.24)$

$--$

Type 2

$10.05(9.44)$

${ }^{\mathrm{a}}$ Depressive symptom (CESD) scores range from 0 to 33. 
Table 2

Pearson Correlations for Diabetes and Non-diabetes Subgroups

\begin{tabular}{llllll}
\hline & 1 & 2 & 3 & 4 & 5 \\
\cline { 2 - 6 } 1. CESD & -- & $-0.053^{*}$ & -0.018 & -0.019 & $0.055^{* *}$ \\
2. Weight & $-0.069^{* * * *}$ & -- & $-0.241^{* * *}$ & $0.096^{* * *}$ & $-0.171^{* * *}$ \\
3. Age & $-0.025^{* * *}$ & $-0.116^{* * *}$ & -- & $-0.380^{* * *}$ & -.015 \\
4. Education & $0.023^{* * *}$ & -0.003 & $-0.398^{* * *}$ & -- & .013 \\
5. Duration & -- & -- & -- & -- & --
\end{tabular}

Note. Non-diabetes subgroup below the diagonal, and diabetes subgroup above the diagonal.

${ }^{*} p<.05 ; * * p<.01 ; * * * p<.001$. 
Table 3

Multiple Linear Regression Predicting Depressive Symptoms (hypothesis 1; N=43,703)

\begin{tabular}{lll}
\hline & \multicolumn{1}{l}{ Unstandardized Coefficient [95\% CI] } & Standard Error \\
\cline { 2 - 3 } Variable & $4.65[4.56-4.74]^{* * *}$ & 0.0444 \\
Intercept & $0.989[0.808-1.169]^{* * *}$ & 0.092 \\
Diabetes & $-0.252[-0.296--0.207]^{* * *}$ & 0.023 \\
Age & $-1.042[-1.136--0.947]^{* * *}$ & 0.048 \\
Gender & $0.058[0.015-0.101]^{*}$ & 0.022 \\
Education & $0.043[-0.005-0.091]$ & 0.024 \\
Weight & $-1.803[-1.894--1.713]^{* * *}$ & 0.046 \\
Marital Status & & 0.056 \\
$R^{2}$ & & $416.83^{* * *}$ \\
$F$ & & \\
\hline
\end{tabular}


Table 4

Multiple Linear Regression, Duration Predicting Depressive Symptoms (hypothesis 1b; diabetes subgroup, $n=2,151$ )

\begin{tabular}{lll}
\hline Variable & Unstandardized Coefficient [95\% CI] & Standard Error \\
\cline { 2 - 3 } Intercept & $6.288[5.894-6.681]^{* * *}$ & 0.201 \\
Age & $-0.468[-0.701--0.234]^{* * *}$ & 0.119 \\
Gender & $-1.042[-1.136-0.947]^{* * *}$ & 0.048 \\
Education & $-0.054[-0.265-0.158]$ & 0.022 \\
Weight & $0.203[-0.025-0.432]$ & 0.116 \\
Marital Status & $-2.462[-2.888--2.03686]^{* * *}$ & 0.217 \\
Duration & $0.313[0.086-0.539]^{* * *}$ & 0.115 \\
$R^{2}$ & & 0.101 \\
$F$ & & $34.55^{* * *}$ \\
\hline$* p<.05 ; * *<.01 ; * * * p<.001$. &
\end{tabular}


Table 5

Multiple Linear Regression, Duration Predicting Depressive Symptoms (Exploratory; Type 2

Diabetes Subgroup, $n=1,865$

\begin{tabular}{lll}
\hline Variable & Unstandardized Coefficient [95\% CI] & Standard Error \\
\hline Intercept & $6.331[5.905-6.757]^{* * *}$ & 0.217 \\
Duration & $0.407[0.131-0.683]^{* *}$ & 0.141 \\
Age & $-0.467[-0.725--0.209]^{* * *}$ & 0.132 \\
Education & $-0.047[-0.276-0.182]$ & 0.117 \\
Weight & $0.217[-0.030-0.464]$ & 0.126 \\
Gender & $-1.830[-2.307--1.352]^{* * *}$ & 0.243 \\
Marital Status & $-2.463[-2.924--2.003]^{* * *}$ & 0.235 \\
$R^{2}$ & & 0.10 \\
$F(6,1858)$ & $34.18 * * *$ \\
\hline$* p<.05 ; * * p .01 ; * * *<.001$. &
\end{tabular}


Table 6

Multiple Linear Regression with Type 2 Diabetes Predicting Depressive Symptoms (hypothesis 2; $n=42,386$ )

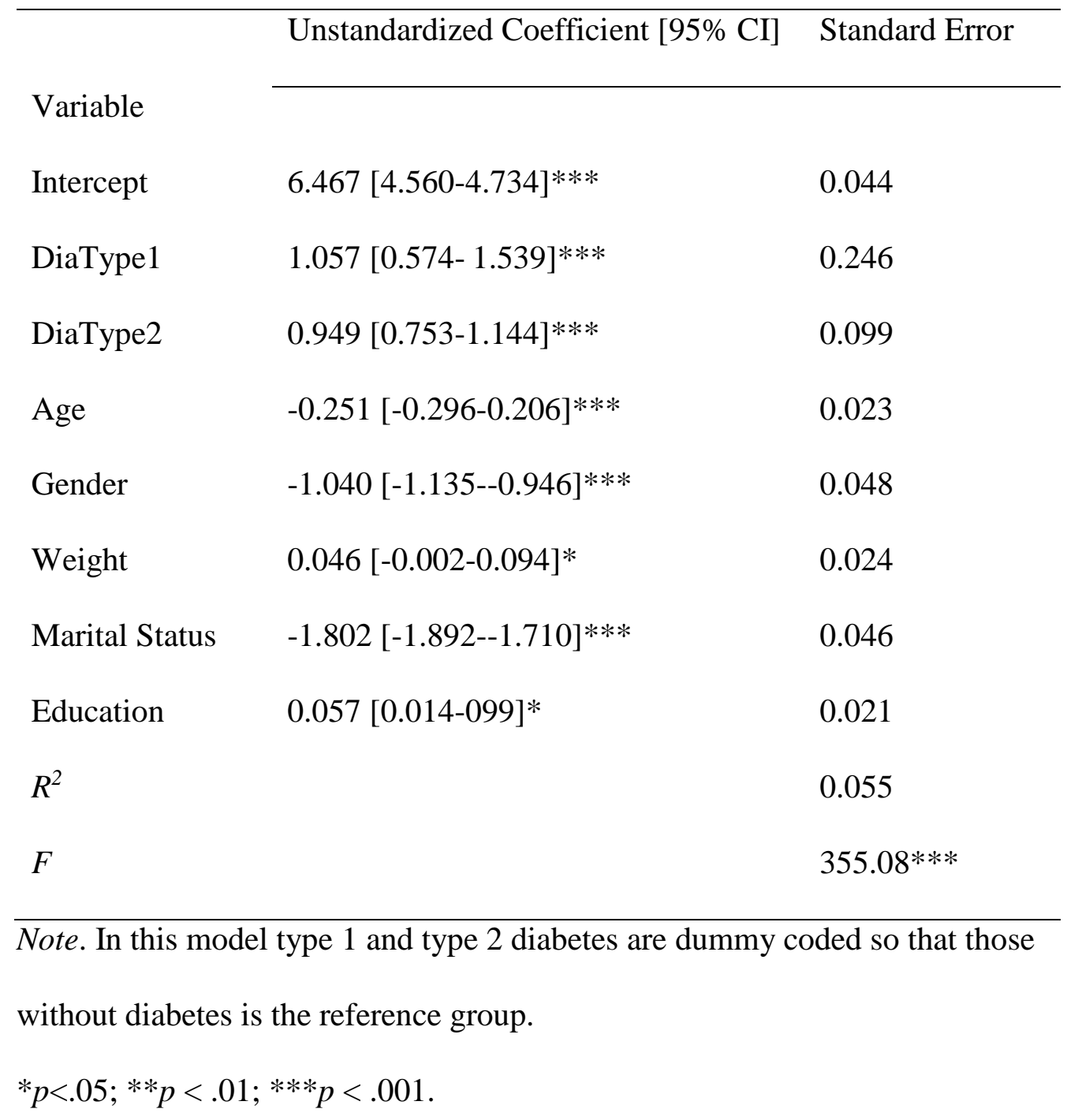


Table 7

Multiple Linear Regression, Type of Diabetes Predicting

Depressive Symptoms (hypothesis 2b; diabetes subgroup, $n=2,151$ )

\begin{tabular}{lll}
\hline & \multicolumn{1}{l}{ Unstandardized Coefficient [95\% CI] } & Standard Error \\
\cline { 2 - 3 } Variable & $5.921[5.202-6.640]^{* * *}$ & \\
Intercept & $0.356[-0.326-1.037]$ & 0.367 \\
DiaType & $0.360[0.133-0.587]^{* *}$ & 0.367 \\
Duration & $-0.459[-0.691--0.226]^{* * *}$ & 0.115 \\
Age & $-1.830[-2.269--1.391]^{* * *}$ & 0.118 \\
Gender & $0.265[0.037-0.493]^{*}$ & 0.224 \\
Weight & $-2.445[-2.869--2.021]^{* * *}$ & 0.116 \\
Marital Status & $-0.088[0.298-122]$ & 0.216 \\
Education & & 0.107 \\
$R^{2}$ & & 0.102 \\
$F$ & & $34.25^{* * *}$ \\
\hline$p p .05 ; * *<.01 ; * * * p .001$. & \\
\hline
\end{tabular}


Table 8

Proportional Hazards Models, Diabetes Predicting Suicide Risk (Hypothesis 4; Full Sample $N=43,703)$

\begin{tabular}{|c|c|c|c|}
\hline \multirow[t]{2}{*}{ Predictors } & Model 1 & \multicolumn{2}{|r|}{ Model 2} \\
\hline & $b$, Hazard ratio $[95 \% \mathrm{CI}]$ & \multicolumn{2}{|c|}{$b$, Hazard ratio $[95 \% \mathrm{CI}]$} \\
\hline Diabetes & $.46[.187-1.130]$ & -0.833 & $.44[0.159-1.191]$ \\
\hline Age & & -1.292 & $.28[0.214-0.353] * * *$ \\
\hline Gender & & 1.248 & $3.49[2.014-6.028]^{* * *}$ \\
\hline Education & & 0.060 & $1.06[0.845-1.335]$ \\
\hline Marital Status & & -0.771 & $.46[0.035-.700]^{* *}$ \\
\hline Weight & & -0.087 & $0.92[0.734-1.144]$ \\
\hline
\end{tabular}

$* * p<.01 ; * * * p<.001$ 
Table 9

Multiple Linear Regression, Interaction of Gender and Diabetes Predicting Depressive Symptoms (Exploratory Analysis; $n=42,428$ )

\begin{tabular}{lll}
\hline Variable & Unstandardized Coefficient $[95 \% \mathrm{CI}]$ & Standard Error \\
\hline Intercept & $4.440[4.278-4.603]^{* * *}$ & .083 \\
Diabetes & $1.423[1.160-1.685]^{* * *}$ & .132 \\
Gender & $-0.998[-1.094--0.091]^{* * *}$ & .049 \\
DiabetesXGender & $-0.811[-1.167--0.454]^{* * *}$ & .182 \\
Age & $-0.253[-0.298--0.209]^{* * *}$ & .023 \\
Marital Status & $-1.802[-1.892--1.711]^{* * *}$ & .046 \\
Education & $0.059[0.017-0.103]^{* *}$ & .022 \\
Weight & $0.040[-0.007-.088]$ & .024 \\
$R^{2}$ & & .056 \\
$F$ & & $360.27 * * *$ \\
\hline$* *<.01 ; * * * p .001$. & &
\end{tabular}


Table 10

Multiple Linear Regression, Interaction of Marital Status and Diabetes Predicting Depressive Symptoms, $n=42,428$

\begin{tabular}{lll}
\hline Variable & Unstandardized Coefficient [95\% CI] & Standard Error \\
\hline Intercept & $4.613[4.524-4.701]^{* * *}$ & 0.045 \\
Diabetes & $1.514[1.207-1.820]^{* * *}$ & 0.156 \\
Marital Status & $-1.756[-1.850--1.663]^{* * *}$ & 0.048 \\
DiabetesXMaritalstatus & $-0.796[-1.172--0.421]^{* * *}$ & 0.192 \\
Age & $-0.252[-0.296--0.208]^{* * *}$ & 0.023 \\
Education & $0.058[0.016-0.110]^{* *}$ & 0.022 \\
Weight & $0.042[-0.005-0.089]$ & 0.024 \\
Gender & $-1.039[-1.134--0.945]^{* * *}$ & 0.048 \\
$R^{2}$ & & 0.056 \\
$F$ & & $359.89 * * *$ \\
\hline$* *<.01 ; * * * p<.001$. & &
\end{tabular}


Table 11

Sample Characteristics for Individuals who Died by Suicide

\begin{tabular}{|c|c|c|}
\hline Variable & Diabetes subgroup & Non-diabetes group \\
\hline Age at Death (years; M, SD) & $66.2(12.98)$ & $63.35(11.04)$ \\
\hline \multicolumn{3}{|l|}{ Gender $n(\%)$} \\
\hline Female & $1(20 \%)$ & $21(23.33 \%)$ \\
\hline Male & $4(80 \%)$ & $69(76.67 \%)$ \\
\hline \multicolumn{3}{|l|}{ Type Diabetes $n(\%)$} \\
\hline Type 1 & $2(40 \%)$ & -- \\
\hline Type 2 & $3(60 \%)$ & -- \\
\hline Duration (years; M, SD) & $24.13(21.94)$ & -- \\
\hline \multicolumn{3}{|l|}{ Marital Status $n(\%)$} \\
\hline Married & $1(20 \%)$ & $43(47.78 \%)$ \\
\hline Unmarried & $4(80 \%)$ & 47 (52.22\%) \\
\hline Education (M, SD) & $10.36(3.25)$ & $10.13(3.29)$ \\
\hline Depressive Symptoms (M, SD) & $7.00(7.07)$ & $6.29(7.10)$ \\
\hline Weight (M, SD) & $181.21(45.79)$ & $168.28(30.01)$ \\
\hline \multicolumn{3}{|l|}{ Vision Impairment $n(\%)$} \\
\hline Yes & $*$ & $5(8.20 \%)$ \\
\hline No & $3(100 \%)$ & $56(91.80 \%)$ \\
\hline
\end{tabular}

* Two people with diabetes who died by suicide do not have vision impairment data 

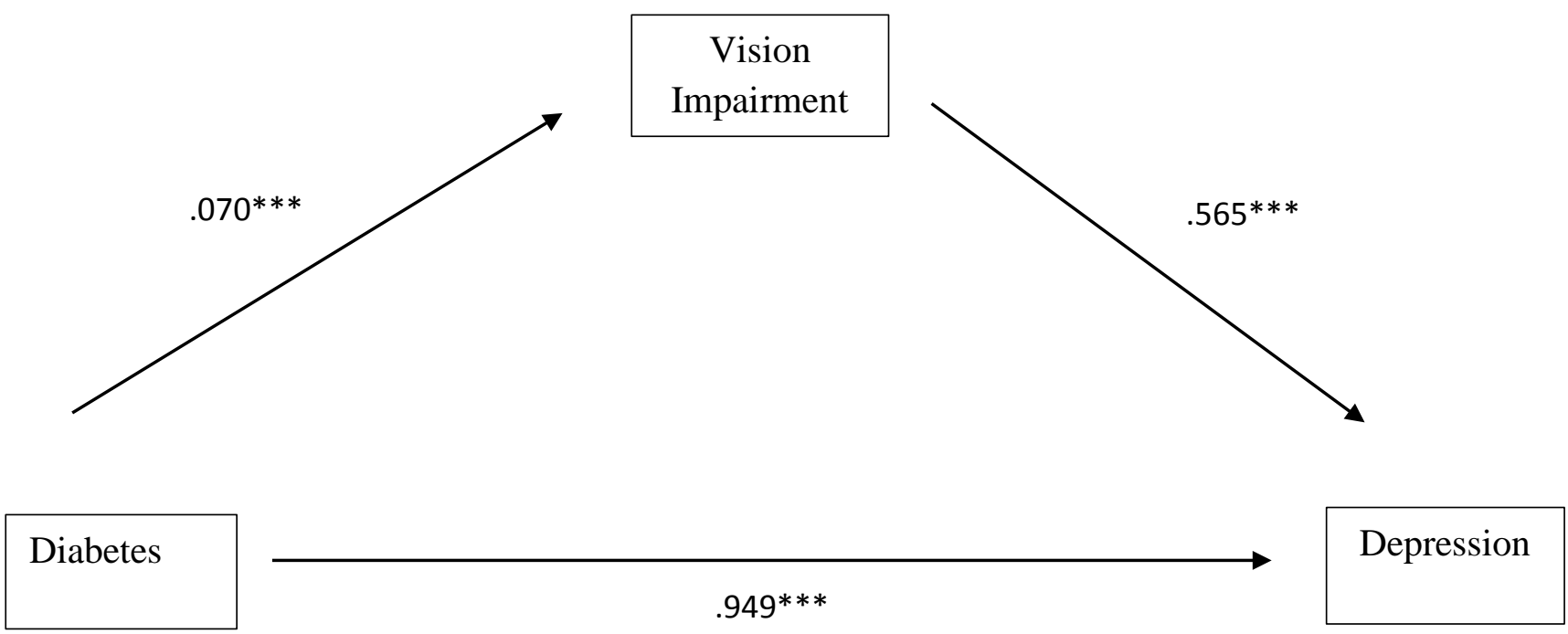

Figure 1. Testing the indirect effect of diabetes on depression through vision impairment ${ }^{*} p<.05 ; * * p<.01 ; * * * p<.001$.

Total effect: $b=0.99[0.787-1.191]^{* * *}$

Indirect effect: $b=0.04[0.022-0.057]^{* * *}$ 


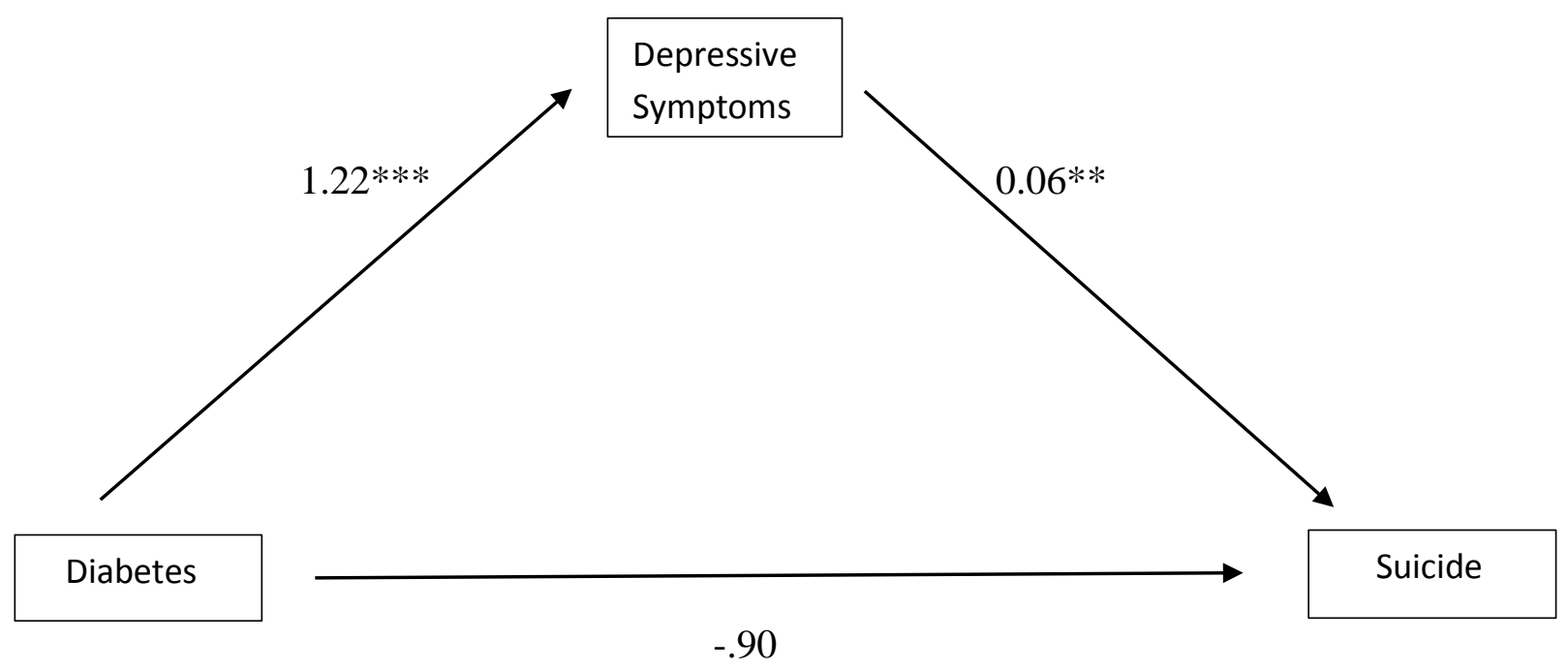

Figure 2. Testing the indirect effect of diabetes on suicide through depressive symptoms $* p<.05 ; * * p<.01 ; * * * p<.001$.

$\mathrm{IE}=.067^{* *} ;$ Total $=-.83, p=.10$ 


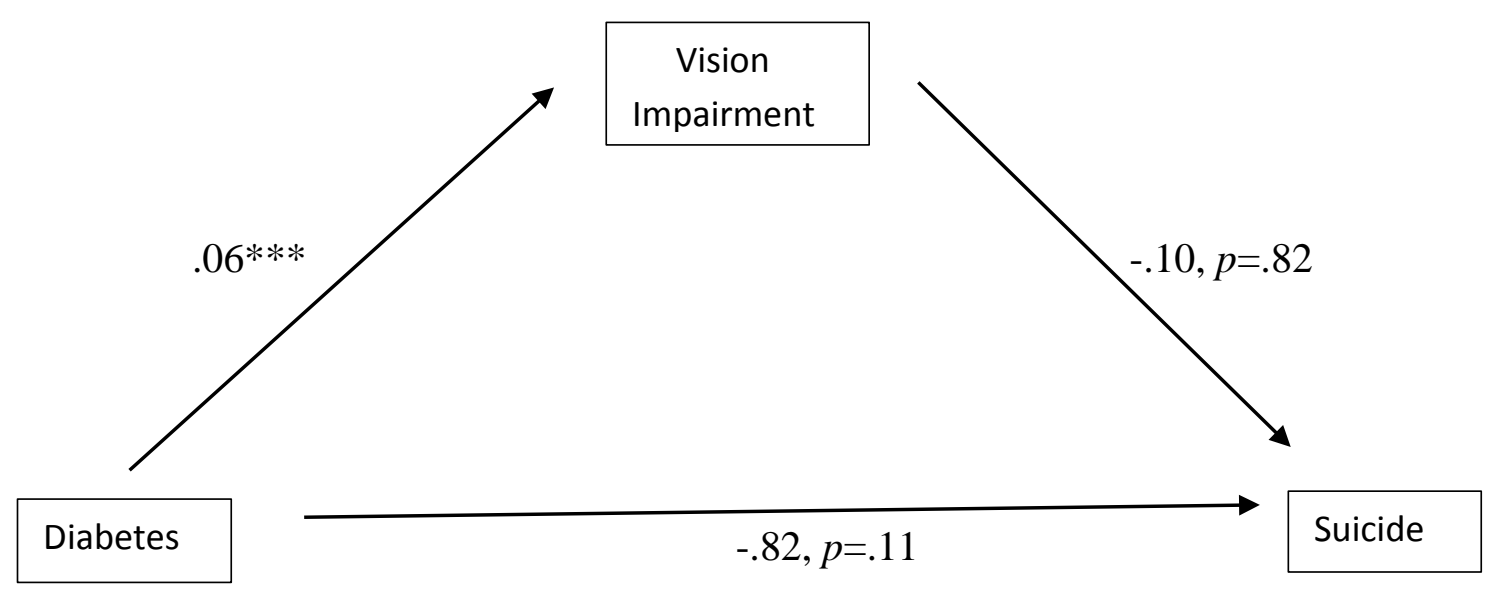

Figure 3. Testing the indirect effect of diabetes on suicide through vision impairment $* p<.05 ; * * p<.01 ; * * * p<.001$. $\mathrm{IE}=-.006^{* *} ;$ Total $=-.83, p=.11$ 


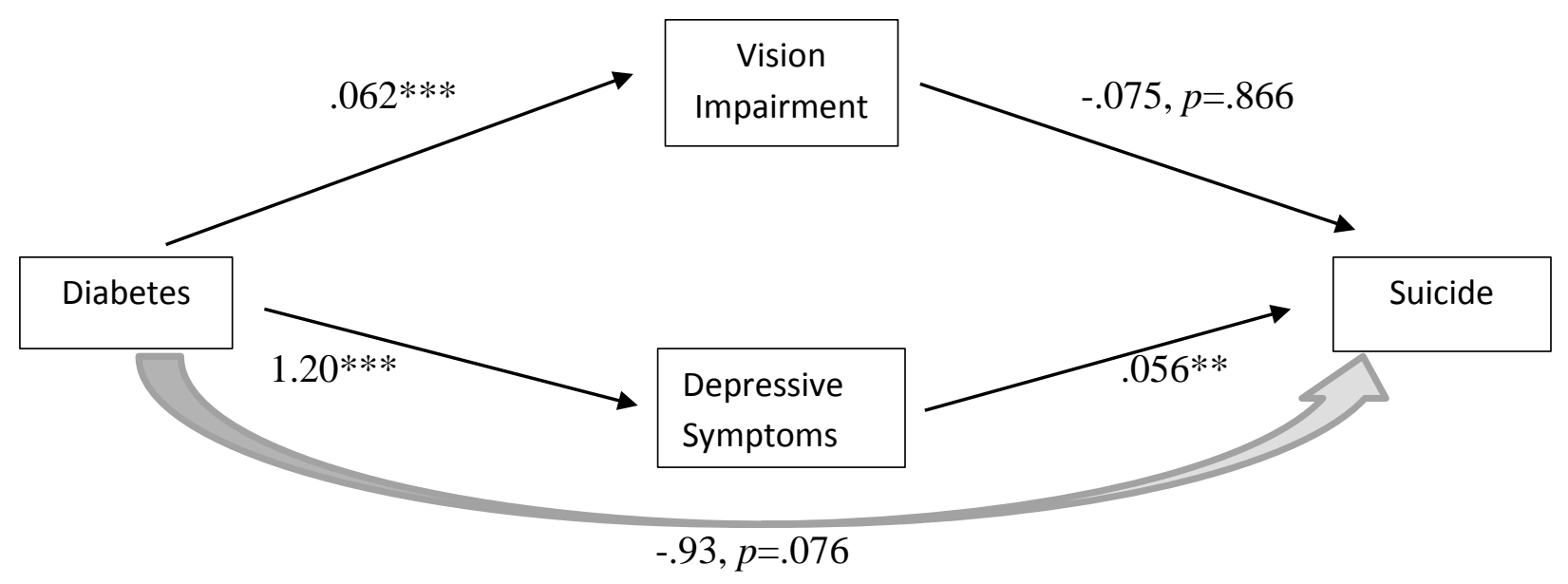

Figure 4. Testing indirect effects of diabetes on suicide through vision impairment and depressive symptoms

${ }^{*} p<.05 ; * * p<.01 ; * * * p<.001$.

$\mathrm{IE}=.063, p=.060 ;$ Total $=-.87, p=.095$ 


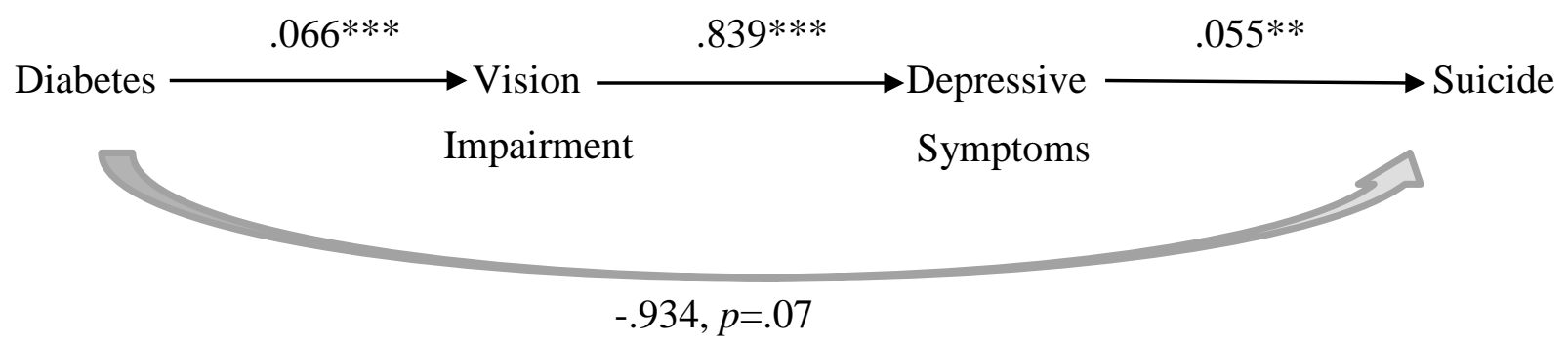

Figure 5. Testing indirect effects of diabetes on suicide through vision impairment first, and depressive symptoms second

${ }^{*} p<.05 ; * * p<.01 ; * * * p<.001$.

$\mathrm{IE}=.049, p=.021 ;$ Total $=-.833, p=.111$ 


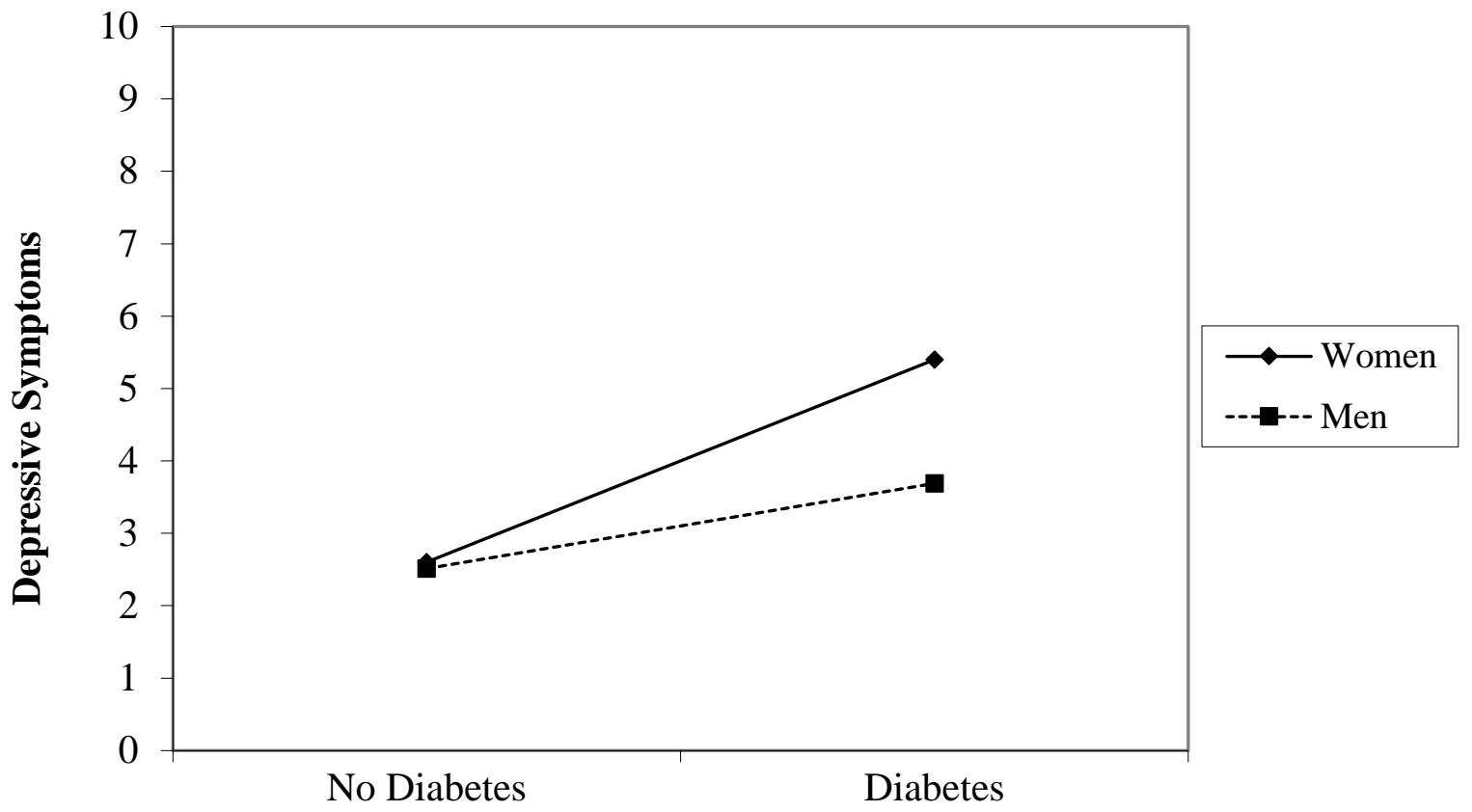

Figure 6. Interaction effect of gender between diabetes and depressive symptoms 


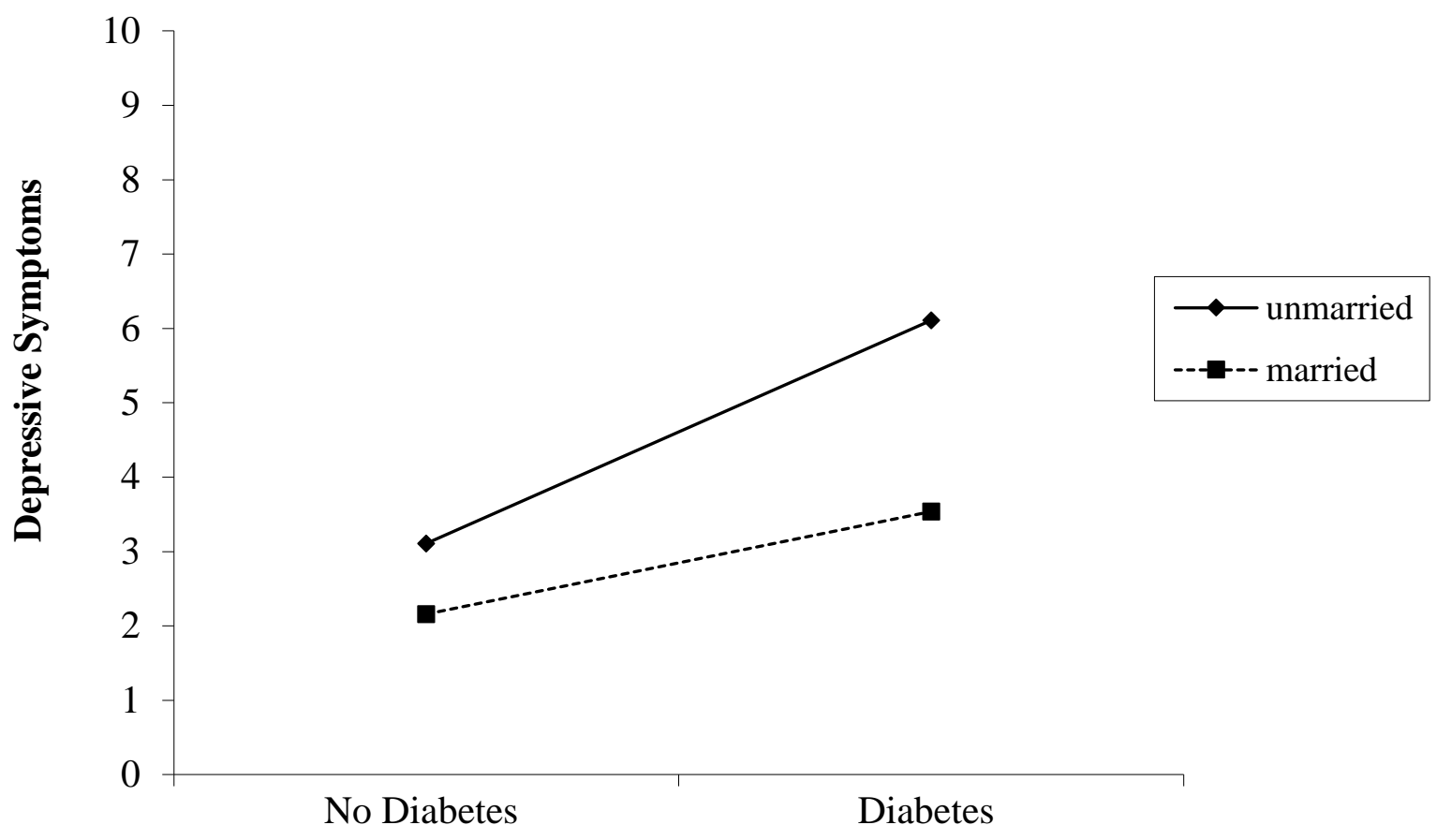

Figure 7. Interaction effect of marital status on diabetes and depressive symptoms 


\section{Appendix A}

\section{SALT items}

Q27

How old are you?

Q28

When were you born?

Q23

What is your current civil status? Are You...?

Married__ separated__ living apart__ cohabitated__ widow/widower__refuse__divorced__ living alone

Q63

Do you have impaired vision?

Both eyes__ One eye__ No__ Don’t know__ Refuse Q75

Do you have or have you had...

Diabetes (including old age) (excluding pregnancy diabetes); Goiter; Glandular disease (including everything but goiter); Gall bladder problem; Gout; Kidney disease

No__ Don’t know__ Refuse

\section{Q121}

How much do you weigh?

Weight in kilograms__ Don’t know__ Refuse 
At what age did you get diabetes? (respondent could answer by stating his/her age or year of diagnosis)

Age_Year__ DK_

Q158

What treatments have you received?

Insulin injections__ Diet__ Pills__

\section{Q159}

What treatments are you getting now?

Insulin injection__ Diet__ Pills__

\section{Q160}

Has the doctor told you which type of diabetes you have?

Adult-onset diabetes__ Juvenile-onset diabetes__ Insulin dependent_ Type 1_ Type II__ NIDDM_ IDDM_ No_

\section{Q617}

What is the highest level of education you completed/working on?

Elementary school__ Primary school__ Secondary school/O-levels__ Girls school__ Military school__ Folk high school__ 2 years of high school__ 3-4 years of high school/A-levels University/college (2 years or less)__ Graduate of university or at college (3 years or more)_ Other__ Don't know__ Refuse 


\section{Appendix B}

\section{1-item Center for Epidemiological Studies-Depression}

For each of the following statements, please tell me if you experienced the feeling during the past week, and if so, how often?

1. You did not feel like eating. Your appetite was poor. Never, seldom, often or always during the past week?

2. You felt depressed. Never, seldom, often or always during the past week?

3. You felt that everything you did was an effort. Never, seldom, often or always during the past week?

4. Your sleep was restless. Never, seldom, often or always during the past week?

5. You were happy. Never, seldom, often or always during the past week?

6. You felt lonely. Never, seldom, often or always during the past week?

7. People were unfriendly. Never, seldom, often or always during the past week?

8. You enjoyed life. Never, seldom, often or always during the past week?

9. You felt sad. Never, seldom, often or always during the past week?

10. You felt that people disliked you. Never, seldom, often or always during the past week?

11. You could not "get going.” Never, seldom, often or always during the past week? 